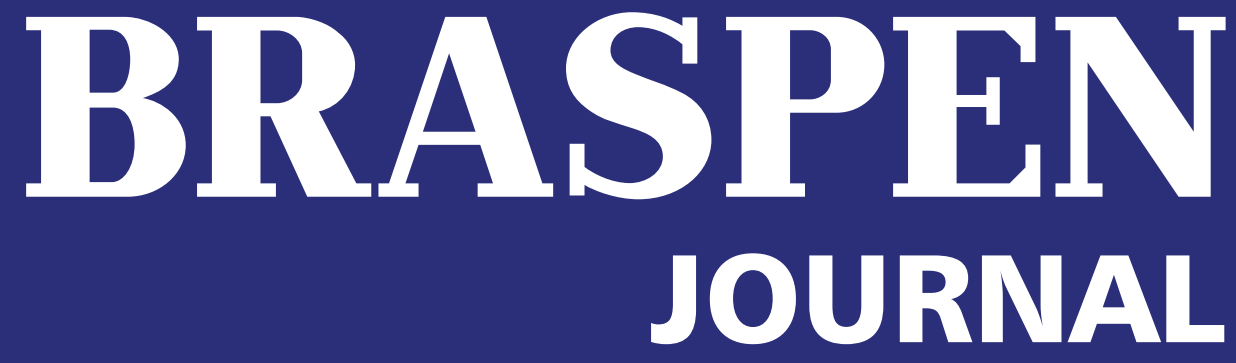
and Enteral Nutrition

\title{
Diretriz BRASPEN de Terapia Nutricional no Paciente com Doença Renal
}





\section{Editor Chefe:}

José Eduardo de Aguilar-Nascimento

Diretor do Curso de medicina, UNIVAG (Várzea Grande, MT, Brasil)

\section{Editora Executiva:}

Paula Pexe Alves Machado

Centro Universitário de Várzea Grande, Cursos de Medicina e Nutrição. (Cuiabá/Várzea Grande, MT, Brasil)

\section{MEMBROS DO CONSELHO EDITORIAL:}

Antonio Carlos Ligocki Campos

Universidade Federal do Paraná, Departamento de Cirurgia do Setor de Ciências da Saúde (Curitiba, PR, Brasil)

Dan Linetzky Waitzberg

Faculdade de Medicina da Universidade de São Paulo, Departamento de Gastroenterologia (São Paulo, SP, Brasil)

Maria Isabel Toulson Davisson Correia

Universidade Federal de Minas Gerais, Departamento de Cirurgia

(Belo Horizonte, BH, Brasil)

\section{EDITORES ASSOCIADOS NACIONAIS}

\section{Médicos}

Cervantes Caporossi

Universidade Federal de Mato Grosso, Centro Universitário de Várzea Grande, Hospital Santa Rosa - Cuiabá-MT

Juliana de Carvalho Machado

Hospital Governador Israel Pinheiro (HGIP)/Instituto de Previdência dos Servidores do Estado de Minas Gerais (IPSEMG)

Fernanda Luisa Ceragioli Oliveira

Escola Paulista de Medicina /UNIFESP - Disciplina de Nutrologia Departamento de Pediatria

Alessandra Miguel Borges

Centro de Pesquisas Oncológicas de Florianópolis (CEPON)

(Florianópolis, SC, Brasil)

Melina Gouveia Castro

Hospital Israelita Albert Einstein (São Paulo, SP, Brasil)

Odery Ramos Júnior

Universidade Federal do Paraná e Faculdade Evangélica de Medicina do Paraná, Disciplina de Gastroenterologia (Curitiba, PR, Brasil)

\section{Pediatria}

Mario Cicero Falcão

Faculdade de Medicina da Universidade de São Paulo, Departamento de Pediatria (São Paulo, SP, Brasil)

Rubens Feferbaum

Faculdade de Medicina da Universidade de São Paulo, Departamento de Pediatria (São Paulo, SP, Brasil)

José Vicente Spolidoro

Pontifícia Universidade Católica do Rio Grande do Sul, Faculdade de Medicina, Departamento de Pediatria (Porto Alegre, RS, Brasil)

\section{Nutricionistas}

Guilherme Duprat Ceniccolla

Hospital de Base de Brasília (Brasília, DF, Brasil)

Leticia Fuganti Campos

Comitê de Nutrição Braspen (PR, Brasil)

Ana Paula Noronha Barrére

Hospital Israelita Albert Einstein (São Paulo, SP, Brasil)

Diana Borges Dock Nascimento

Universidade Federal de Mato Grosso, Departamento de Nutrição (Cuiabá, MT, Brasil)

\section{Silvana Paiva Orlandi}

Universidade Federal de Pelotas, Faculdade de Nutrição (Pelotas, RS, Brasil)

Simone Vasconcelos Generoso

Universidade Federal de Minas Gerais, Departamento de Nutrição (Belo Horizonte, MG, Brasil)

\section{Enfermeiros}

Sandra Regina Maciqueira

Universidade do Estado do Rio de Janeiro - UERJ, Faculdade de Enfermagem (Rio de janeiro, RJ, Brasil)

Jaqueline Almeida Guimaraes Barbosa

Universidade Federal de Minas Gerais-UFMG, Departamento de Enfermagem Básica (Belo Horizonte, MG, Brasil)

Claudia Satiko Takemura Matsuba

Hospital do Coração-São Paulo, Equipe Multiprofissinal Terapia Nutricional - EMTN (São Paulo, SP, Brasil)

Leticia Faria Serpa

Hospital Alemão Oswaldo Cruz (São Paulo, SP, Brasil)

\section{Bióloga}

Raquel Susana Matos de Miranda Torrinhas

Faculdade de Medicina da Universidade de São Paulo, Departamento de Gastroenterologia (São Paulo, SP, Brasil)

\section{EDITORES ASSOCIADOS INTERNACIONAIS}

Alessandro Laviano

University of Rome (Roma, Itália)

Andrew Ukleja

Department of Gastroenterology at Cleveland Clinic Florida (Weston, Florida, EUA)

\section{Carla Prado}

University of Alberta (Alberta, Canadá)

Carol Ireton Jones

Nutrition Therapy Specialist, Carrollton, Texas (Carrollton, Texas, EUA)

Gordon Jensen

University of Vermont College of Medicine (Burlington, Vermont, EUA)

Nicolas Velasco

Pontifical Catholic University of Chile (Santiago, Chile)

Luiza Kent Smith

University of Saskatchewan (Saskatoon, Saskatchewan, Canada)

Paula Alves

Instituto Portugues de Oncologia do Porto de Francisco Gentil (IPOPFG-E.P.E) (Porto, Portugal)

Remy Meier

Medical University Hospital Liestal (Liestal, Switzerland)

Robert Martindale

Oregon Health \& Science University (Eugene, Oregon, EUA)

Stephen McClave

University of Louisville (Louisville, Kentucky, EUA)

Vanessa Fuchs

Universidad ANAHUAC and UNAM (Cidade do México, México)

\section{COMITÊ CONSULTIVO}

\section{Joel Faintuch}

Faculdade de Medicina da Universidade de São Paulo, Departamento de Gastroenterologia (São Paulo, SP, Brasil)

Steven B. Heymsfield

Pennington Biomedical Research Center (Baton Rouge, Louisiana, EUA)

\section{Secretária:}

Vanice Silva de Oliveira Freitas

\section{Revisora Científica:}

Rosangela Monteiro

Projeto Gráfico, Diagramação e Revisão:

Criativa Comunicação e Editora

\section{Impressão:}

Pontograf 


\title{
JBRASPEN SBNPE
}

\section{Brazilian Society of Parenteral and Enteral Nutrition}

\author{
www.braspen.org
}

PRESIDENTE:

Melina Gouveia Castro

VICE-PRESIDENTE

Diogo Oliveira Toledo

\section{PRIMEIRO SECRETÁRIO}

\section{SEGUNDA SECRETÁRIA}

Clarissa Martins Saraiva Figueira Zambell

\section{PRIMEIRO TESOUREIRO}

Liane Brescovici Nunes de Matos

\section{SEGUNDA TESOUREIRA}

Juliana Tepedino Martins Alves

\section{CONSELHO FISCAL}

Paulo César Ribeiro

Silvio José de Lucena Dantas

Suely Itsuko Ciosak

Alberto José de Barros Neto

Lucas Lima de Carvalho

\section{CONSELHO CONSULTIVO}

Ricardo Schilling Rosenfeld

Diana Borges Dock Nascimento

Nara Lucia Andrade Lopes

Karla Lopes Pereira Gomes

Simone Araújo

Marcia de Souza Antunes

Mario Jorge Sobreiro

José Vicente Noronha Spolidoro

COMITÊ DE DEFESA PROFISSIONAL

Fabiano Girade Correa

Maria Carolina Gonçalves Dias

Marcia de Souza Antunes
Jaqueline Almeida Guimarães Barbosa

Ana Maria Furkim

\section{COMITÊ DE FARMÁCIA}

Presidente:

Wander Campos

Vice-Presidente:

Michel Kfouri Filho

Secretário:

Claudete Jacyzen

COMITÊ DE NUTRIÇÃO
Presidente:
Leticia Fuganti Campos
Vice-Presidente:
Guilherme Duprat Ceniccola
Secretária:
Priscilla Alves Barreto

\section{COMITÊ DE ENFERMAGEM}

Presidente:

Cláudia Satiko Takemura Matsuba

Vice-Presidente:

Andreia Maria Minutti de Almeida

Secretária:

Fernanda Ramires Tott

\section{COMITÊ DE FONOAUDIOLOGIA}

Presidente:

Maria de Fatima Lago Alvite

Vice-Presidente:

Irene de Pedro Netto

Secretária:

Christiane Lopes de Albuquerque

\author{
COMITÊ DA CRIANÇA E DO ADOLESCENTE \\ Presidente: \\ Daniela Gomes \\ Vice-Presidente: \\ Fernanda Luisa Ceragioli Oliveira \\ Secretária: \\ Cláudia Bezerra de Almeida
}

\author{
COMITÊ DE REABILITAÇÃO INTESTINAL \\ Presidente: \\ Silvio Dantas \\ Vice-Presidente: \\ Maria de Lourdes Teixeira da Silva \\ Secretário: \\ João Wilney Franco Filho
}

\author{
COMITÊ DE ASSISTÊNCIA DOMICILIAR \\ Presidente: \\ Nara Lucia Andrade Lopes \\ Vice-Presidente: \\ Denise Philomene Joseph Van Aanholt \\ Secretária: \\ Cristiane D' Almeida
}

MEMBROS DO COMITÊ EDUCACIONAL
Robson Freitas De Moura
José Eduardo Aguilar Nascimento
Diogo Oliveira Toledo
Letícia Faria Serpa
Ricardo Tadeu Prete
Sérgio Henrique Loss
Ana Paula Noronha Barrere
Silvia Maria Fraga Piovacari
Lindinalda de França Rocha
Décio dos Reis Ribeiro

\section{Sociedade Brasileira de Nutrição Parenteral e Enteral}

BRASPEN Journal, ISSN 2525-7374, é órgão oficial de divulgação da Sociedade Brasileira de Nutrição Parenteral e Enteral (BRASPEN).

Disponível on line: http://www.braspen.org/braspen-journal

Responsabilidade legal: A Sociedade Brasileira de Nutrição Parenteral e Enteral e os editores do BRASPEN Journal não podem ser responsabilizados por erros, danos ou por qualquer consequência de lesão a pacientes ou indivíduos derivados do uso das informações contidas nesta publicação. Os pontos de vista e as opiniões expressas pelos autores não necessariamente refletem aqueles do corpo editorial; tampouco a publicação de anúncios constitui qualquer endosso da Sociedade Brasileira de Nutrição Parenteral e Enteral ou do Corpo Editorial aos produtos anunciados pelos fabricantes.

C 2021 Copyright: Todos os direitos reservados. Os artigos podem ser reproduzidos para uso pessoal. Nenhuma outra modalidade de publicação pode reproduzir os artigos publicados sem a prévia permissão, por escrito, da Sociedade Brasileira de Nutrição Parenteral e Enteral.

Endereço para correspondência: BRASPEN Journal. Rua Abílio Soares, 233 Conjunto 144 - São Paulo, SP, Brasil - CEP: 04005-000 Telefone: (11) 3889-9909 - E-mail: revista@braspen.org 


\title{
DIRETRIZ BRASPEN DE TERAPIA NUTRICIONAL NO PACIENTE COM DOENÇA RENAL
}

\author{
AUTORES \\ Clarissa Martins Saraiva Figueira Zambelli \\ Rodrigo Costa Gonçalves \\ Juliana Tepedino Martins Alves \\ Guilherme Teixeira de Araújo \\ Renata Cristina Campos Goncalves \\ Maria Helena Lima Gusmão \\ Ana Adélia Cavalcante Hordonho \\ Fernando das Mercês de Lucas Júnior \\ Juliano Antunes Machado \\ Juliana de Carvalho Machado \\ Marcelo Mazza do Nascimento \\ Cristina Martins
}




\begin{tabular}{|c|c|c|c|}
\hline Academy: & Academia de Nutrição e Dietética dos EUA & KDOQI: & Kidney Disease Outcomes Quality Initiative \\
\hline ASBRAN: & Associação Brasileira de Nutrição & MCC: & Malnutrition Clinical Characteristics \\
\hline AVD: & Atividades de vida diária & \multirow[b]{2}{*}{ MIS: } & \\
\hline BIA: & Bioimpedância & & $\begin{array}{l}\text { Malnutrition Inflammation Score (Escore .. } \\
\text { de Desnutrição-Inflamação) }\end{array}$ \\
\hline BIS: & Bioimpedância por espectroscopia & \multirow[t]{2}{*}{ MST: } & \multirow{2}{*}{$\begin{array}{l}\text { Malnutrition Screening Tool (Instrumento } \\
\text { de Triagem de Desnutrição) }\end{array}$} \\
\hline \multirow[t]{2}{*}{ BRASPEN: } & \multirow{2}{*}{$\begin{array}{l}\text { Sociedade Brasileira de Nutrição Parenteral } \\
\text { e Enteral) }\end{array}$} & & \\
\hline & & NE: & Nutrição enteral \\
\hline CC: & Circunferência da cintura & NP: & Nutrição parenteral \\
\hline $\mathrm{Cl}:$ & Calorimetria indireta & NPID: & Nutrição parenteral intradialítica \\
\hline DBES: & Diálise de baixa eficiência sustentada & \multirow[t]{2}{*}{ PNA: } & \multirow{3}{*}{$\begin{array}{l}\text { Protein equivalent nitrogen appearance } \\
\text { rate (taxa de aparecimento do nutrogênio } \\
\text { equivalente à proteína) }\end{array}$} \\
\hline DEXA: & Densitometria óssea & & \\
\hline DP: & Diálise peritoneal & \multirow{3}{*}{$\begin{array}{l}\text { PTH: } \\
\text { RDA: }\end{array}$} & \\
\hline DRA: & Doença renal aguda & & \multirow{2}{*}{$\begin{array}{l}\text { Paratormônio } \\
\text { Recommended Dietary Intakes (Ingestões } \\
\text { Alimentares Recomendadas) }\end{array}$} \\
\hline DRC: & Doença renal crônica & & \\
\hline GER: & Gasto energético de repouso & SBN: & \multirow[t]{2}{*}{ Sociedade Brasileira de Nefrologia } \\
\hline GPID: & Ganho de peso interdialítico & Scored & \\
\hline GRADE: & $\begin{array}{l}\text { Grading of Recommendations, Assessment, } \\
\text { Development and Evaluation }\end{array}$ & \multirow[t]{2}{*}{ PG-SGA: } & \multirow{4}{*}{$\begin{array}{l}\text { Scored Patient Generated Subjective } \\
\text { Global Assessment (Avaliação Global } \\
\text { Subjetiva Gerada pelo Paciente } \\
\text { Pontuada) } \\
\text { Subjective Clobal Assessment (Avaliação } \\
\text { Clobal Subjetiva) }\end{array}$} \\
\hline HD: & Hemodiálise & & \\
\hline HDC: & Hemodiálise contínua & \multirow{2}{*}{ SGA: } & \\
\hline HDFC: & Hemodiafiltração contínua & & \\
\hline HDFC: & Hemodiafiltração contínua & SNO: & Suplemento nutricional oral \\
\hline HDFVVC: & Hemodiafiltração venovenosa contínua & TFG: & Taxa de filtração glomerular \\
\hline HFC: & Hemofiltração contínua & TR: & Transplante renal \\
\hline HFVVC: & Hemofiltração venovenosa contínua & TRR: & Terapia de reposição renal \\
\hline IC: & Índice de conicidade & TRRC: & Terapia de reposição renal contínua \\
\hline IMC: & Índice de massa corporal & UFCS: & Ultrafiltração contínua sustentada \\
\hline IRA: & Injúria renal aguda & UTI: & Unidade de terapia intensiva \\
\hline
\end{tabular}




\section{Sumário}

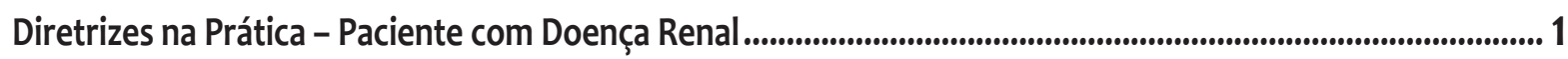

Practice Guidelines - Kidney Disease Patient

Diretriz BRASPEN de Terapia Nutricional no Paciente com Doença Renal..................................................................2

BRASPEN Guidelines on Nutritional Therapy in Patients with Kidney Disease

Apoio institucional da Sociedade Brasileira de Nefrologia (SBN) e Associação Brasileira de Nutrição (ASBRAN)

Clarissa Martins Saraiva Figueira Zambelli

Rodrigo Costa Conçalves

Juliana Tepedino Martins Alves

Guilherme Teixeira de Araújo

Renata Cristina Campos Concalves

Maria Helena Lima Gusmão

Ana Adélia Cavalcante Hordonho

Fernando das Mercês de Lucas Júnior

Juliano Antunes Machado

Juliana de Carvalho Machado

Marcelo Mazza do Nascimento

Cristina Martins 


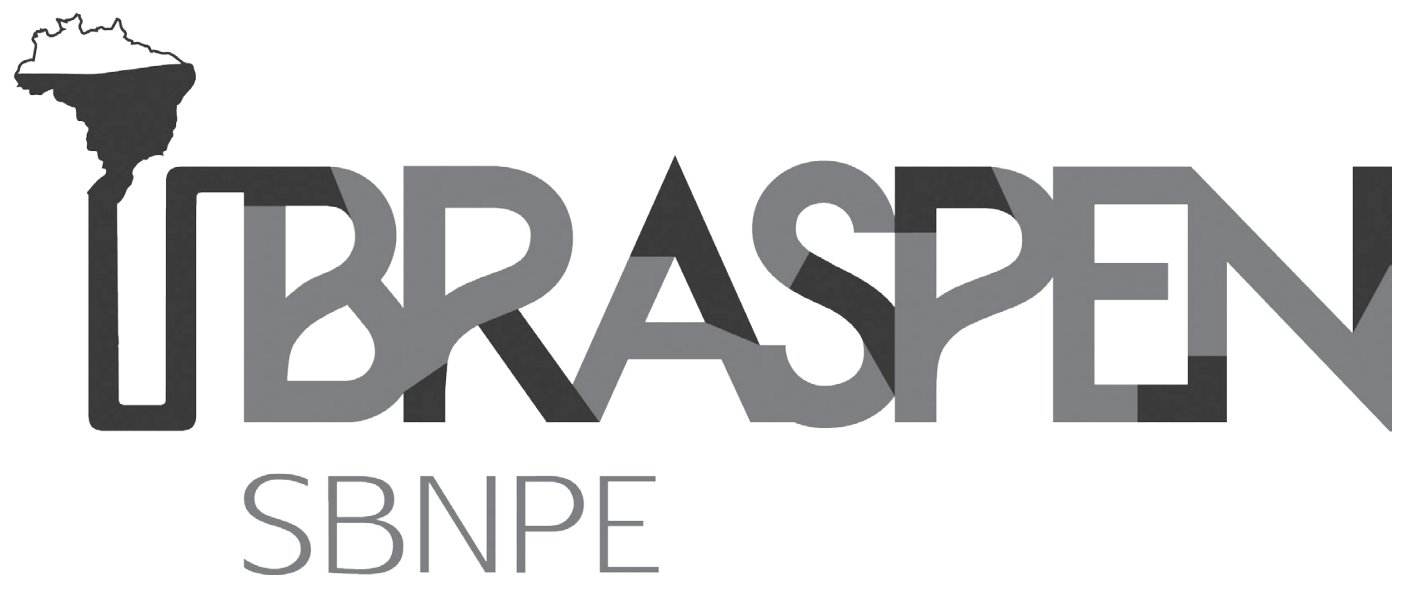

CITE OS ARTIGOS DO BRASPEN JOURNAL NAS SUAS PUBLICAÇÕES. AS CITAÇÕES ROBUSTECERÃO NOSSAS CHANCES DE INDEXAÇÃO. 


\section{Apresentação}

\section{Diretrizes na Prática - Paciente com Doença Renal}

\section{Practice Guidelines - Kidney Disease Patient}

É com grande satisfação que anunciamos neste suplemento do BRASPEN Journal mais uma atualização das Diretrizes Brasileiras de Terapia Nutricional (DITEN). A Diretriz BRASPEN de Terapia Nutricional no Paciente com Doença Renal é baseada em evidências e foi preparada por um grupo de especialistas de diferentes Sociedades, incluindo a BRASPEN, a Sociedade Brasileira de Nefrologia (SBN) e a Associação Brasileira de Nutrição (ASBRAN).

Esta diretriz apresenta respostas a 21 questões específicas, de relevância para a prática da terapia nutricional no paciente renal, onde cada resposta resultou em nível de evidência, claro e objetivo, seguindo as condutas do sistema GRADE, e conta ainda com um quadro com a lista das recomendações que foram discutidas posteriormente. A Diretriz aborda questões que vão desde a triagem e diagnóstico nutricional no paciente renal até a terapia nutricional em situações específicas, como gravidez ou em pediatria.

As Diretrizes em Nutrição Clínica formulam linhas de tratamento baseadas no contexto multidisciplinar, promovem a uniformização das práticas de terapia nutricional, racionalizam seu uso e, consequentemente, podem reduzir custos e beneficiar o paciente renal, tanto com doença aguda quanto crônica.

Parabenizo às Sociedades que contribuíram com essa Diretriz e também aos autores dessa atualização, por todo o esforço e empenho em atualizar e uniformizar conceitos e cuidados no paciente com doença renal, garantindo que os nossos pacientes recebam a terapia nutricional dentro dos mais elevados padrões científicos nacionais e internacionais.

\section{José Eduardo de Aguilar-Nascimento e Paula Pexe A Machado² \\ 'Editor Chefe \\ ${ }^{2}$ Editora Executiva}




\title{
Diretriz BRASPEN de Terapia Nutricional no Paciente com Doença Renal
}

\author{
BRASPEN Guidelines on Nutritional Therapy in Patients with Kidney Disease \\ Apoio institucional da Sociedade Brasileira de Nefrologia (SBN) e Associação Brasileira de Nutrição (ASBRAN)
}

\section{DOI: $10.37111 /$ braspenj.diretrizRENAL}

Clarissa Martins Saraiva Figueira Zambelli

Rodrigo Costa Gonçalves ${ }^{2}$

Juliana Tepedino Martins Alves ${ }^{3}$

Guilherme Teixeira de Araújo ${ }^{4}$

Renata Cristina Campos Goncalves ${ }^{5}$

Maria Helena Lima Gusmãó

Ana Adélia Cavalcante Hordonho ${ }^{7}$

Fernando das Mercês de Lucas Júnior ${ }^{8}$

Juliano Antunes Machado?

Juliana de Carvalho Machado 10

Marcelo Mazza do Nascimento"1

Cristina Martins ${ }^{12}$

\section{INTRODUÇ̃̃O}

As doenças renais agudas e crônicas são altamente prevalentes e representam causas importantes de morbidade e mortalidade nos pacientes afetados por essas enfermidades. A taxa de mortalidade pode ser elevada em algumas situações, e variável de acordo com fatores etiológicos e estado clínico. Assim, a abordagem nutricional desses pacientes é complexa, pois eles representam um grupo heterogêneo, com características metabólicas e necessidades nutricionais distintas.

O objetivo desta diretriz é fornecer recomendações baseadas em evidências sobre o cuidado nutricional de pacientes com doença renal aguda e crônica. A presente diretriz é uma atualização de recomendações previamente publicadas pela Sociedade Brasileira de Nutrição Parenteral e Enteral (BRASPEN), em 2011 . Ela é baseada em diretrizes internacionais e nacionais recentes, e estudos atuais de relevância científica, e foi preparada por um grupo de especialistas de diferentes áreas, que envolveu a BRASPEN, a Sociedade Brasileira de Nefrologia (SBN) e a Associação Brasileira de Nutrição (ASBRAN).

Esta diretriz foi elaborada de forma a apresentar respostas a questões específicas, previamente definidas pelos autores, que nortearam o conteúdo aqui apresentado. Cada resposta resultou em nível de evidência, claro e objetivo. $\bigcirc$ sistema Grading of Recommendations, Assessment, Development and Evaluation (GRADE) foi utilizado para uniformizar as recomendações ${ }^{\top}$. Este define, de forma objetiva, o nível (qualidade) de evidência científica da recomendação a ser adotada, ou não, em determinada conduta. $O$ nível de evidência representa a confiança na informação utilizada. No sistema GRADE, a avaliação da qualidade da evidência é realizada para cada desfecho analisado, com utilização de conjunto disponível de evidência. No sistema, a qualidade da evidência é classificada em quatro níveis: alto, moderado, baixo e muito baixo (Quadro 1).
Endereço para correspondência: Clarissa Martins Saraiva Figueira Zambelli Rua Abílio Soares, 233, ci 144 - Paraíso São Paulo, SP, Brasil - CEP: 04005-000 E-mail: clarissamartinszambelli@gmail.com

1 Especialista em Terapia Nutricional Parenteral e Enteral (Braspen), Cirurgia Geral e especialização em Nutrologia (Abran). Sociedade Brasileira de Nutrição Parenteral e Enteral (BRASPEN), Rede Mater Dei de Saúde, Instituto Mário Penna, Equipe de Terapia Nutricional Avançada - ETERNA, Belo Horizonte, MG, Brasil.

2 Especialista em Nutrologia e Medicina Intensiva e Nutrição Parenteral e Enteral. Sociedade Brasileira de Nutrição Parenteral e Enteral (BRASPEN), Equipe Nutrir Terapia Nutricional, Hospital HUGOL, Hospital Orion, Goiânia, GO, Brasil.

3 Especialista em Nutrologia pela ABRAN e Terapia Nutricional pela Braspen. Sociedade Brasileira de Nutrição Parenteral e Enteral (BRASPEN), Hospital Sírio Libanês - Unidade Brasília, Hospital Brasília, Equipe NUTEP Terapia Nutricional, Brasília, DF, Brasil.

4 Mestre em Clínica Médica pela Faculdade de Medicina de Ribeirão Preto da Universidade de São Paulo (FMRP-USP). Sociedade Brasileira de Nutrição Parenteral e Enteral (BRASPEN), Hospital HOME; Equipe NUTEP Terapia Nutricional, Brasília, DF, Brasil.

5 Especialista em Terapia Nutricional e Nutricão Clinica - Braspen. Especialização em Terapia Nutricional e Nutrição Clinica- Ganep. Especialização em Docência no Ensino Super- Uninove". Sociedade Brasileira de Nutrição Parenteral e Enteral (BRASPEN), Ganep Educação, São Paulo, SP, Brasil.

6 Doutora em Medicina e Saúde pela Faculdade de Medicina - UFBA. Sociedade Brasileira de Nefrologia (SBN), Universidade Federal da Bahia (UFBA) Escola de Nutrição/Complexo Hospitalar Universitário Professor Edgard Santos, Salvador, BA, Brasil.

7 Nutricionista especialista em clínica e terapêutica nutricional pela Universidade de Uniguaçu e mestre em epidemiologia dos agravos nutricionais pela Universidade Federal de Alagoas (UFAL). Sociedade Brasileira de Nefrologia (SBN), Associação Brasileira de Nutrição (ASBRAN), Hospital Escola Hélvio Auto da Universidade Estadual de Ciências da Saúde, Hospital Metropolitano, Maceió, AL, Brasil.

8 Médico especialista em nefrologista. Sociedade Brasileira de Nefrologia (SBN), Senviço de Transplante Renal do Hospital das Clínicas da Universidade Federal de Minas Gerais, Belo Horizonte, MG, Brasil.

9 Especialista em terapia nutricional, (SBNPE/BRASPEN), gastroenterologia (FBG) e clínica médica (SBCM). Sociedade Brasileira de Nutrição Parenteral e Enteral (BRASPEN), Rede Mater Dei de Saúde, Equipe de Terapia Nutricional Avançada - ETERNA, Belo Horizonte, MG, Brasil.

10 Doutora em Clinica Medica da Faculdade Medicina da USP de Ribeirão Preto. Sociedade Brasileira de Nutrição Parenteral e Enteral (BRASPEN), Terapia Nutricional do Hospital Governador Israel Pinheiro - Instituto de Previdência dos Servidores do Estado de Minas Gerais (IPSEMG), Belo Horizonte, MG, Brasil.

11 Doutor em Nefrologia, Setor Ciencias da Saude UFRGS. Sociedade Brasileira de Nefrologia (SBN), Universidade Federal do Paraná, Curitiba, PR, Brasil.

12 Doutora em Ciências Médicas pela Universidade Federal do Rio Grande do Sul. Sociedade Brasileira de Nefrologia (SBN), Associação Brasileira de Nutrição (ASBRAN), Instituto Cristina Martins de Educação e Pesquisa em Nutrição, Curitiba, PR, Brasil. 


\begin{tabular}{|c|c|c|c|}
\hline Nível & Definição & Implicações & Fonte de informação \\
\hline Alto & $\begin{array}{l}\text { Há forte confiança de que o } \\
\text { verdadeiro efeito esteja } \\
\text { próximo daquele estimado }\end{array}$ & $\begin{array}{l}\text { É improvável que trabalhos } \\
\text { adicionais irão modificar a } \\
\text { confiança na estimativa do efeito }\end{array}$ & $\begin{array}{l}\text { - Ensaios clínicos randomizados bem delineados, } \\
\text { com amostras representativas } \\
\text { - Em alguns casos, estudos observacionais bem } \\
\text { delineados, com achados consistentes* }\end{array}$ \\
\hline Moderado & $\begin{array}{l}\text { Há confiança moderada no } \\
\text { efeito estimado }\end{array}$ & $\begin{array}{l}\text { Trabalhos futuros poderão mudar a } \\
\text { confiança na estimativa de efeito, } \\
\text { podendo modificar a estimativa }\end{array}$ & $\begin{array}{l}\text { - Ensaios clínicos com limitações leves }{ }^{\star \star} \\
\text { - Estudos observacionais bem delineados, com } \\
\text { achados consistentes* }\end{array}$ \\
\hline Baixo & A confiança no efeito é limitada & $\begin{array}{l}\text { Trabalhos futuros provavelmente } \\
\text { terão impacto importante em nossa } \\
\text { confiança na estimativa do efeito }\end{array}$ & $\begin{array}{l}\text { - Ensaios clínicos com limitações moderadas }{ }^{\star \star} \\
\text { - Estudos observacionais comparativos: coorte e } \\
\text { caso-controle }\end{array}$ \\
\hline Muito Baixo & $\begin{array}{l}\text { A confiança na estimativa de } \\
\text { efeito é muito limitada. } \\
\text { Há importante grau de } \\
\text { incerteza nos achados }\end{array}$ & $\begin{array}{l}\text { Qualquer estimativa de efeito é } \\
\text { incerta }\end{array}$ & $\begin{array}{l}\text { - Ensaios clínicos com limitações graves }{ }^{\star \star} \\
\text { - Estudos observacionais comparativos com presença } \\
\text { - Es limitações }{ }^{\star \star} \\
\text { - Estudos observacionais não comparativos }{ }^{\star \star *} \\
\text { Opinão de especialistas }\end{array}$ \\
\hline
\end{tabular}

Fonte: Elaboração GRADE Working Group: <http://www.gradeworkinggroup.org>

*Estudo de coorte sem limitações metodológicas, com achados consistentes, apresentando tamanho de efeito grande e/ou gradiente dose-resposta.

**Limitações: vieses no delineamento do estudo, inconsistência nos resultados, desfechos substituídos ou validade externa comprometida.

***Séries e relatos de casos.

Apesar das recomendações aqui apresentadas (Quadro 2) serem pautadas em evidências e opinião de especialistas, reforça-se que decisões clínicas devem, sempre, ser baseadas no julgamento profissional, de acordo com condições clínicas, circunstâncias locais e individuais de cada paciente.

Quadro 2 - Lista de recomendações.

\section{Triagem e Avaliação}

1. Não há instrumento de triagem específico para pacientes com doenças renais crônicas e agudas. $O$ Instrumento de Triagem de Desnutrição, conhecido como MST (Malnutrition Screening Tool), pode ser recomendado para a triagem de risco de desnutrição.

2. Não há indicador isolado para diagnóstico de desnutrição. Os indicadores recomendados mais importantes são: perda involuntária de peso, índice de massa corporal (IMC) baixo $\left(<18 \mathrm{~kg} / \mathrm{m}^{2}\right)$, ingestão de energia e proteínas abaixo do recomendado, e redução da força e funcionalidade muscular. Para o diagnóstico de obesidade, o excesso de gordura abdominal é o indicador mais importante.

3. O instrumento recomendado para diagnosticar desnutrição é a SGA (Subjective Global Assessment) tradicional.

\section{Injuria Renal Aguda (IRA)}

4. A recomendação de energia para pacientes com IRA é $20-30 \mathrm{kcal} / \mathrm{kg} / \mathrm{dia}$ de peso seco ou ideal (em caso de obesidade ou muito baixo peso). Em estresse grave, a recomendação é $20-25 \mathrm{kcal} / \mathrm{kg} / \mathrm{dia}$. A nutrição hipocalórica (<70\% do gasto energético) é recomendada na fase inicial da enfermidade aguda, com aumento para $80 \%$ a $100 \%$ da meta depois de, aproximadamente, três dias.

5. A recomendação de proteínas para pacientes hipercatabólicos com IRA e sem terapia de reposição renal (TRR) é de 1,3-1,5 g/kg/dia. Em TRR intermitente, a recomendação é de cerca de 1,5 g/kg/dia. Em TRR contínua, deve ser de 1,7-2,5 g/kg/dia. Proteínas não devem ser restringidas para pacientes hipercatabólicos com objetivo de evitar ou retardar o início de TRR. Porém, pode ser controlada para aqueles não hipercatabólicos e sem necessidade de TRR, com recomendação em torno de 0,8-1,0 g/kg/dia.

6. A suplementação de glutamina não é indicada para pacientes hipercatabólicos com IRA.

7. A suplementação de micronutrientes é recomendada para pacientes com IRA em TRR.

8. O manejo de eletrólitos de pacientes com IRA deve ser individualizado, de acordo com os níveis séricos. A necessidade de reposição depende de resultados séricos de cada paciente e de cada eletrólito. Níveis elevados podem indicar necessidade de TRR.

9. Formulações padrão de nutrição enteral e/ou parenteral são recomendadas para pacientes hipercatabólicos com IRA e/ou em TRR. Formulações com restrição de eletrólitos podem ser indicadas de acordo com a necessidade individual. 
Continuação Quadro 2 - Lista de recomendações.

\section{Doença Renal Crônica (DRC)}

10. A recomendação de energia é de $25-35 \mathrm{kcal} / \mathrm{kg} / \mathrm{dia}$ para pacientes metabolicamente estáveis, baseado em idade, sexo, atividade física, estado nutricional, estágio da DRC e comorbidades associadas.

11. A recomendação de proteínas para adultos com DRC 3-5 é de 0,6-0,8 $\mathrm{g} / \mathrm{kg} / \mathrm{dia}$, com aporte energético adequado. A variação mais baixa é recomendada para preservação da função renal de pacientes sem risco nutricional. A taxa mais elevada tem o mesmo objetivo, mas contempla a necessidade daqueles com diabetes mellitus, desnutrição, idade avançada e/ou outras condições de risco. Para adultos com DRC G5D, em hemodiálise (HD) ou diálise peritoneal (DP), a recomendação proteica é de 1,2 g/kg/dia, com ingestão energética adequada.

12. A dieta com, aproximadamente, $0,3-0,4 \mathrm{~g} / \mathrm{kg} /$ dia de proteína suplementada com cetoanálogos, ou aminoácidos essenciais, para pacientes com DRC G4-5 diminui o risco de falência renal, reduz proteinúria, e pode ter efeitos benéficos sobre complicações metabólicas, sem causar prejuízos no estado nutricional.

13. Embora as proteínas de origem vegetal possam ter ação biológica positiva e possível benefício clínico para pacientes com DRC, as evidências são insuficientes para recomendar a substituição de proteínas animais por vegetais. Efeitos benéficos podem estar associados não somente ao tipo de proteína, mas ao padrão dietético, baseado em maior proporção de alimentos de origem vegetal.

14. Para pacientes adultos com DRC G3-5D, a ingestão alimentar de fósforo deve ser ajustada para manter os níveis séricos do mineral dentro da normalidade. Restrição deve ser indicada na presença de hiperfosfatemia persistente e progressiva, e após a avaliação, também, de níveis séricos de cálcio e paratormônio (PTH). A intervenção em nutrição deve considerar não somente a quantidade de fósforo, mas suas fontes dietéticas e a presença de aditivos em alimentos processados. A ingestão alimentar de potássio, de forma prudente, deve ser ajustada para manter os níveis séricos dentro da normalidade. A ingestão alimentar de sódio é recomendada em $<2,3 \mathrm{~g} / \mathrm{dia}$, em conjunto com intervenções farmacológicas aplicáveis.

15. O ganho de peso interdialítico (GPID) recomendado em HD é de 2-4\% do peso corporal seco. A ingestão diária recomendada de líquidos depende do GPID.

16. A ingestão alimentar de pacientes com DRC G3-5D deve suprir a necessidade de vitaminas e oligoelementos da mesma forma que para a população saudável. A suplementação individualizada é indicada quando a avaliação ou monitoramento em nutrição indicarem risco ou presença de deficiência. Pacientes DRC G5D apresentam perdas durante o procedimento dialítico e podem necessitar de suplementação quando a ingestão alimentar estiver insuficiente por períodos longos de tempo. Vitaminas lipossolúveis devem ser suplementadas somente em caso de deficiência.

17. Suplemento nutricional oral (SNO) é recomendado quando a ingestão somente com a dieta não alcança as necessidades de energia e proteína, e há risco ou presença de desnutrição. Formulações padrão de SNO são recomendadas, exceto em casos de alterações metabólicas que exijam ajustes na composição química.

18. A nutrição enteral (NE) é indicada para pacientes adultos com DRC G3-5D, quando a ingestão oral (dieta e SNO) estiver insuficiente para alcançar as necessidades de energia e nutrientes, e exista risco ou presença de desnutrição. Formulações especializadas podem ser indicadas de acordo com necessidades individuais do paciente.

19. A nutrição parenteral intradialítica (NPID) é indicada para pacientes em HD, quando a ingestão da dieta e SNO não alcança as necessidades de energia e nutrientes, e há risco ou presença de desnutrição.

\section{Situações Especiais}

20. A recomendação de energia para gestantes com DRC G1-5 é de $35 \mathrm{kcal} / \mathrm{kg} / \mathrm{dia}$, com uso do peso pré-gestacional. Devem ser acrescentadas $85 \mathrm{kcal} /$ dia no primeiro, $275 \mathrm{kcal} / \mathrm{dia}$ no segundo e $475 \mathrm{kcal} / \mathrm{dia}$ no terceiro trimestre de gestação. Para gestantes com DRC G5 em HD é de 25-35 kcal $/ \mathrm{kg} / \mathrm{dia}$, e em DP, é de $25 \mathrm{kcal} / \mathrm{kg} / \mathrm{dia}$. A recomendação de proteína para gestantes com DRC G1-2 é semelhante às mulheres saudáveis. Para DRC G3-4, a recomendação é de 0,6-0,8 g/kg/dia com 6-10 g adicionais de proteína, aminoácidos ou cetoanálogos. Para pacientes com DRC 5D, a recomendação é de $1,2 \mathrm{~g} / \mathrm{kg} /$ dia para $H D$ e $1,4 \mathrm{~g} / \mathrm{kg} /$ dia para DP.

21. As recomendações de energia e proteínas para crianças com DRC G2-5 são semelhantes àquelas saudáveis, para a idade cronológica, mas no limite mais alto recomendado. Não é recomendada restrição proteica para crianças e adolescentes com DRC 3-5D.

22. A recomendação de energia para idosos com DRC é de 25-35 kcal $/ \mathrm{kg} / \mathrm{dia}$, e a de proteínas para aqueles com DRC G4-5 é de 0,6-0,8 g/kg/ dia. A dieta muito baixa em proteína $(0,3 \mathrm{~g} / \mathrm{kg} / \mathrm{dia})$, associada à suplementação com cetoanálogos, parece segura. A recomendação proteica para idosos com DRC G5D, em HD ou DP, é de 1,2-1,5 g/kg/dia.

23. A recomendação de energia e nutrientes depende do período do transplante renal (TR). A recomendação média de energia é de 25-35 kcal/ $\mathrm{kg} / \mathrm{dia}$. No TR imediato e em caso de rejeição aguda do enxerto, a recomendação de proteínas é de 1,3-1,5 g/kg de peso atual ou ideal. No pós-TR tardio, a recomendação é em torno de 0,8 $\mathrm{g} / \mathrm{kg} / \mathrm{dia}$. A restrição de 0,6 g/ $\mathrm{kg} /$ dia pode ser considerada em caso de rejeição crônica. 


\section{CARACTERÍSTICAS GERAIS}

Os rins são órgãos reguladores que, seletivamente, excretam e conservam água e vários compostos químicos. As suas funções principais são: 1) manutenção do balanço hídrico, da osmolaridade, das concentrações de eletrólitos (ex.: sódio, potássio, cloreto, cálcio, magnésio e fosfato) e do estado acidobásico do organismo; 2) excreção de produtos finais do metabolismo, como ureia, ácido úrico, fosfatos e sulfatos, e também de outras substâncias, fármacos e drogas; 3) produção e secreção de hormônios e enzimas envolvidas na hemodinâmica sistêmica e renal (renina, angiotensina II, prostaglandinas e bradicinina), na maturação de hemácias na medula óssea (eritropoietina), no balanço de cálcio e fósforo, bem como o metabolismo ósseo (por conta da ativação da vitamina D). Para manter a homeostasia, os rins devem estabelecer equilíbrio entre a taxa de aparecimento e de desaparecimento de determinada substância no organismo (quantidade produzida + quantidade ingerida $=$ quantidade consumida + quantidade excretada).

Atualmente, as terminologias para doenças renais e distúrbios agudos e crônicos estão em processo de padronização². Terminologias atuais estão apresentadas no Quadro 3.
IRA. Medicamentos inibidores de conversão da angiotensina, bloqueadores de receptor da angiotensina e anti-inflamatórios não esteroides, geralmente, estão envolvidos na redução da perfusão renal. Na IRA, há aumento da creatinina sérica em $\geq 50 \%$ dentro de sete dias, ou elevação da creatinina sérica em $\geq 0,3 \mathrm{mg} / \mathrm{dL}$ dentro de 48 h, ou oligúria ${ }^{2}$. Pode apresentar três estágios, de acordo com creatinina sérica e/ou critérios de produção de urina. Pelo fato de, frequentemente, ser causada por enfermidade grave, a taxa de mortalidade em IRA é extremamente alta, e pode variar de $10 \%$ a $80 \%$, de acordo com o estado geral dos pacientes e fatores etiológicos ${ }^{3}$. As infecções e as complicações cardiorrespiratórias são as causas mais frequentes de morte.

De acordo com a taxa de filtração glomerular (TFG), a DRC é classificada em estágios, ou grupos: $G 1=\geq 90, G 2$ $=60$ a 89, G3a $=45$ a 59, G3b $=30$ a 44, G4 = 15 a $29, \mathrm{G} 5=<15 \mathrm{~mL} / \mathrm{min}$ por 1,73 $\mathrm{m}^{2}, \mathrm{G} 5 \mathrm{D}=$ diálise $^{2}$. A DRC G1-2 é definida pela evidência de dano renal, usualmente albuminúria (>30 mg/g ou $>3 \mathrm{mg} / \mathrm{mmol}$ ), com TFG $>60$ $\mathrm{mL} / \mathrm{min} / 1,73 \mathrm{~m}^{2}$. Já a DRC G3-5 compreende variações mais baixas e progressivas da TFG.

Quadro 3 - Definições de doença renal aguda e crônica.

\begin{tabular}{|c|c|c|}
\hline Enfermidade Renal & Critério Funcional & Critério Estrutural \\
\hline Doença Renal Crônica (DRC) & TFG $<60 \mathrm{~mL} / \mathrm{min}$ por $1,73 \mathrm{~m}^{2}$ por $\geq 3$ meses & Dano renal $\geq 3$ meses \\
\hline Sem Doença Renal & $\begin{array}{l}\text { TFG } \geq 60 \mathrm{~mL} / \mathrm{min} \text { por } 1,73 \mathrm{~m}^{2} \\
\text { Creatinina sérica estável sem IRA/DRA/DRC }\end{array}$ & Sem dano renal \\
\hline
\end{tabular}

Fonte: adaptado de Levey et al. ${ }^{2}$.

A injúria renal aguda (IRA) é uma síndrome, caracterizada pelo declínio rápido e repentino da função renal, com acúmulo de metabólitos, toxinas e medicamentos no sangue. Também ocorre alteração nas funções intrínsecas dos rins. $O$ espectro de sintomas e eventos é muito amplo e variável. Pode ocorrer anúria, mas também volume urinário elevado. A IRA é uma subcategoria da doença renal aguda (DRA) ${ }^{2}$, que corresponde à perda da função renal em até três meses. Quando a disfunção persiste por mais de três meses, é identificada como doença renal crônica (DRC). Em UTI, sepse é a causa mais comum de
As TRR incluem diálise e transplante renal (TR), e podem ser de curto e de longo prazo ${ }^{2}$. As principais modalidades dialíticas são: HD, diálise peritoneal (DP, ambulatorial ou automatizada), hemofiltração venovenosa contínua (HFVC) e hemodiafiltração venovenosa contínua (HDFVC). A frequência pode ser contínua ou intermitente (curta ou prolongada).

Há modalidades de TRR que são prolongadas, em comparação com as sessões de diálise intermitente tradicionais, mas não são contínuas. Estas incluem a DBES e a ultrafiltração contínua sustentada (UFCS). A DBES usa a 
difusão para remover soluto, mas em intervalo mais longo do que a HD intermitente. A UFCS usa a convecção, com taxa de ultrafiltração mais baixa do que hemofiltração contínua (HFC), principalmente para remover volume do paciente. Aparentemente, não há nenhuma modalidade de terapia de reposição renal contínua (TRRC) superior à outra. A seleção depende da preferência da instituição, da condição hídrica e das anormalidades metabólicas e eletrolíticas.

As TRRC são indicadas para pacientes com IRA, quando há instabilidade hemodinâmica e/ou em necessidade de remoção agressiva de líquido (ultrafiltração). Além disso, podem ser indicadas quando há hipercatabolismo grave, e o aporte nutricional pode precipitar hipervolemia ou uremia. Embora haja avanços tecnológicos, as TRRC continuam sendo complexas, e impõem perdas ou ganhos significativos de macronutrientes, micronutrientes e eletrólitos ${ }^{4}$.

Nas TRRC, dois mecanismos podem ser aplicados para a remoção de soluto: a difusão e a convecção. Na difusão, a solução de dialisato corre contra a corrente sanguínea, no filtro de diálise. Na convecção (ultrafiltração), há gradiente alto de pressão transmembrana no hemofiltro, que força a passagem da água do plasma para dentro de uma membrana semipermeável, que arrasta soluto com ela. A convecção é eficaz para a remoção de solutos de tamanho molecular pequeno e médio. A convecção permite a remoção de solutos maiores, comparada à difusão. A quantidade de glicose contida nos líquidos de reposição, necessários para repor o que foi removido pela convecção, pode afetar significativamente o ganho ou a perda de calorias ao paciente. $\mathrm{Na}$ HFWC e na HDFVC, são usados líquidos de reposição, com objetivo de repor eletrólitos e volume plasmático, removidos durante a convecção. Quando administrados pré-filtro, há perda menor de nutrientes no circuito. Já soluções de dialisato são usadas na hemodiálise contínua (HDC) e na hemodiafiltração contínua (HDFC), com objetivo de atingir o clearance difusivo do soluto. Devido ao tempo de contato prolongado entre o sangue e o circuito de TRRC extracorpóreo, o uso de anticoagulante é recomendado para prevenir a coagulação do filtro e otimizar a permeabilidade e a eficiência da diálise ${ }^{4}$.

Diversas composições com eletrólitos e tampão podem ser utilizadas como líquidos de reposição. $O$ dialisato é selecionado com bases no perfil metabólico, acidobásico e eletrolítico de cada paciente. Os líquidos de reposição e dialisatos à base de bicarbonato têm sido preferidos, ao invés de lactato, para correção da acidose. No dialisato, o conteúdo de glicose varia de 0 a $110 \mathrm{mg} / \mathrm{dL}$, e afeta a sua distribuição total ${ }^{4}$. Os líquidos sem glicose podem contribuir para perdas totais dela no efluente, enquanto aqueles com glicose têm impacto mínimo. A distribuição de glicose depende da taxa de infusão. E pode ser, ou não, utilizado coagulante. Quando usado, o tipo mais comum é o citrato, na ausência de contraindicações, ou a heparina ${ }^{4}$. $\bigcirc$ citrato quela cálcio dentro do circuito e, com isso, cessa a cascata de coagulação. Quando houver necessidade de recuperação da concentração sanguínea de cálcio, ele é infundido pós-filtro. $\bigcirc$ citrato pode ser fonte significativa de calorias. Quando o sangue do circuito da TRRC é infundido de volta à circulação sistêmica, o citrato é rapidamente metabolizado em bicarbonato pelo fígado, músculo e rim.

O estado nutricional tem papel fundamental na saúde e nos desfechos clínicos de pacientes com doença renal. Não há dúvidas que a desnutrição tem alta prevalência e está intimamente associada a resultados clínicos adversos e aumento da taxa de hospitalização, complicações e mortalidade nessa população $0^{5,6}$.

Já o papel da obesidade na mortalidade ainda precisa ser melhor esclarecido. Está claro que o problema está associado diretamente ao risco de desenvolvimento da DRC, além de promover hipertensão, diabetes, resistência periférica à insulina, dislipidemia e albuminúria. Estudo observacional, com acompanhamento de 30 anos de 13.496 indivíduos, demonstrou que a obesidade (avaliada pelo IMC, taxa cintura/quadril e \% de gordura corporal inicial), no meio da vida (média de idade de 54 anos), foi associada com declínio da TFG em mulheres brancas e negras, mas não em homens ${ }^{7}$. Em coorte prospectivo, pacientes obesos e com anormalidades metabólicas (hipertensão, hiperglicemia ou diabetes, dislipidemia e inflamação) apresentaram associação significativa com risco de progressão da $\mathrm{DRC}^{8}$. Já estudo menor, prospectivo e com duração de 4,9 anos, revelou que a obesidade (IMC $\left.>30 \mathrm{~kg} / \mathrm{m}^{2}\right)$ ou a \% alta de gordura corporal ( $>25 \%$ para homens e $>35 \%$ para mulheres) não teve impacto na progressão da DRC G3-G5\%.

Em diálise, particularmente em HD, o IMC elevado tem sido inversamente correlacionado com mortalidade (epidemiologia reversa ou "paradoxo da obesidade"). Estudo em $\mathrm{HD}$ demonstrou que a mortalidade diminuiv, com o IMC entre 40 e $<45 \mathrm{~kg} / \mathrm{m}^{2}$, em $31 \%{ }^{10}$. Comparado a 25 a $<27,5 \mathrm{~kg} /$ $\mathrm{m}^{2}$, o IMC baixo, menor que $18 \mathrm{~kg} / \mathrm{m}^{2}$, aumentou 3,2 vezes o risco de morte. Estudo prospectivo multicêntrico, de 2.833 pacientes coreanos em HD, evidenciou correlação do IMC elevado com sobrevida em homens, mas não em mulheres ${ }^{11}$. Medidas repetidas da composição corporal pela densitometria óssea (DEXA) em pacientes com DRC demonstraram que gordura corporal mais elevada está associada com melhor sobrevida $^{12}$. Em DP, a maior quantidade de massa gorda também foi diretamente associada com melhor sobrevida ${ }^{13}$. Por outro lado, estudo demonstrou que pacientes com IMC mais elevado, em DP, tiveram necessidade mais rápida de transferência para HD, maior tempo para oportunidade de transplante e maior incidência de hospitalização relacionada à peritonite ${ }^{14}$. Além disso, apresentaram perda mais rápida da função renal residual. Houve formato em $U$ entre o IMC e a mortalidade, mas a maior sobrevida foi com IMC entre 
30 a $35 \mathrm{~kg} / \mathrm{m}^{2}$, em HD, e de $\geq 35 \mathrm{~kg} / \mathrm{m}^{2}$, em DP. Especificamente para pacientes com diabetes, o estudo demonstrou que a obesidade grave reduziu a sobrevida. Aparentemente, a distribuição pode ser mais importante do que a \% de gordura ou $\mathrm{IMC}$ em relação à mortalidade em diálise. $\mathrm{O}$ acompanhamento de 48 meses mostrou que a circunferência abdominal e o aumento dela ao longo do tempo foram diretamente associados com mortalidade em DP15.

\section{TRIAGEM E AVALIAÇÃO NUTRICIONAL}

\section{Questão 1 - Há instrumentos de triagem de desnutrição específicos para pacientes com IRA ou DRC?}

Recomendação 1: Não há instrumento de triagem específico para pacientes com doenças renais crônicas e agudas. $O$ Instrumento de Triagem de Desnutrição, conhecido como MST (Malnutrition Screening Tool), pode ser recomendado para a triagem de risco de desnutrição.

\section{Nível de evidência: Baixo para IRA e moderado para $\underline{D R C}$}

A triagem, geralmente, serve para identificar o risco de desnutrição. Um instrumento para o objetivo deve ser simples e independente da doença, idade ou local de aplicação. Ou seja, deve ser validado para uso universal, + e pode ser aplicado em qualquer ambiente de prática e por diversos profissionais ou leigos treinados.

Há inúmeros instrumentos de triagem de risco nutricional desenvolvidos e/ou validados para pacientes com DRC, embora não haja para IRA. O Kidney Disease Outcomes Quality Initiative (KDOQI)/Academy 2020 não sugere instrumento específico para triagem de risco de desnutrição para pacientes com DRC ${ }^{16}$. Porém, uma revisão sistemática recente demonstrou que o MST (Malnutrition Screening Tool - Instrumento de Triagem de Desnutrição) teve os melhores graus de validade, concordância e confiabilidade, independentemente de idade, história clínica ou local de atendimento do paciente ${ }^{17}$. $O$ instrumento tem boa generalização e foi validado para pacientes em cuidados crônicos e agudos, hospitalizados, ambulatoriais e em reabilitação ${ }^{18-20}$. A simplicidade do MST permite que o instrumento seja aplicado pelo próprio paciente, familiares e cuidadores, além de profissionais da saúde. Estudo revelou que o MST foi confiável e válido para identificar, com acurácia, o risco de desnutrição quando conduzido por pacientes ambulatoriais com câncer, comparado ao instrumento sendo aplicado por nutricionistas ${ }^{19}$.

\section{Questão 2 - Quais indicadores de diagnóstico de desnutrição e obesidade são recomenda- dos para pacientes com doença renal?}

\begin{abstract}
Recomendação 2: Não há indicador isolado para diagnóstico de desnutrição. Os indicadores recomendados mais importantes são: perda involuntária de peso, IMC baixo $\left(<18 \mathrm{~kg} / \mathrm{m}^{2}\right)$, ingestão de energia e proteínas abaixo do recomendado, e redução da força e funcionalidade muscular. Para o diagnóstico de obesidade, o excesso de gordura abdominal é o indicador mais importante.
\end{abstract}

\section{Nível de evidência: Alto}

Não há indicador único para avaliação do estado nutricional de pacientes com doença renal, e muitos são difíceis de ser interpretados na presença de enfermidade hepática, hiperhidratação, anemia e inflamação crônica. Vários sinais físicos, como alterações dermatológicas e oculares, não têm causa nutricional, mas da uremia. $\bigcirc$ peso corporal medido pode não ser acurado, devido à retenção hídrica. Mas a perda não intencional maior que 10\%, nos últimos seis meses, é considerada significativa para diagnóstico de desnutrição. O KDOQI/Academy $2020^{16}$ sugere usar julgamento clínico para determinar o método de medição do peso corporal (ex.: medido, histórico de alterações, medições em série; ajustes para suspeita de impacto de edema, ascite e órgãos policísticos), devido à ausência de normas de referência padrão. Também sugere que, para pacientes adultos com DRC G $1-5$ e G5D em HD ou DP, é razoável considerar o baixo peso, baseado no IMC $<18 \mathrm{~kg} / \mathrm{m}^{2}$, como preditor de mortalidade mais elevada ${ }^{16}$. Outro indicador importante para diagnóstico de desnutrição é a ingestão de energia e proteína. Estudo retrospectivo revelou que a ingestão baixa de energia foi associada com pior sobrevida em período de dez anos ${ }^{21}$. A ingestão proteica de pacientes estáveis com DRC pode ser avaliada pela cinética da ureia. A protein equivalent nitrogen appearance rate (PNA) está relacionada com mortalidade ${ }^{22}$. Para adultos com DRC G1-5D, o KDOQI/Academy refere que a PNA e a PNA normalizada podem ser usadas para complementação da avaliação em nutrição, mas não devem ser interpretadas isoladamente, pois são influenciadas por fatores não nutricionais ${ }^{16}$. $O$ GPID $<2 \%$ pode indicar baixa ingestão alimentar, e também foi associado com aumento da mortalidade em pacientes em HD ${ }^{23}$. Assim como o peso, a avaliação de quantidade das massas muscular e gordurosa tem limitações para pacientes com doença renal. As dobras cutâneas do tríceps, subescapular e outras, avaliam a espessura do tecido adiposo subcutâneo nos membros e no tronco. Elas são sugeridas pelo KDOQI/Academy ${ }^{16}$ para pacientes adultos com DRC G1-5D que não apresentem 
edema. Comparado à DEXA, estudo de pacientes com DRC G3-4 revelou que as dobras cutâneas demonstraram boa reprodutibilidade, mas subestimaram a gordura corporal no início e depois de seis meses ${ }^{24}$. A bioimpedância (BIA) e a bioimpedância por espectroscopia (BIS) têm sido usadas para monitorar o estado de hidratação e estabelecer metas de peso seco em pacientes com DRC G1-G5D25. De acordo com o KDOQI/Academy ${ }^{16}$, a BIA de multifrequência pode ser usada para avaliar a composição corporal de adultos com DRC G5D em HD. Neste caso, é ideal que seja realizada depois de, pelo menos, 30 minutos do término da sessão, para permitir redistribuição dos líquidos corporais. Para adultos com DRC G3-5 ou G5D em DP, não há evidências suficientes para sugerir a BIA para avaliar a composição corporal. Já o ângulo de fase baixo (em torno de $4,6^{\circ}$ ) foi associado à desnutrição e à maior mortalidade em diálise ${ }^{26,27}$. $\bigcirc$ índice de creatinina avalia a cinética dela, mas é insatisfatório para avaliar a massa corporal magra. Um dos problemas é que ele reflete a soma da ingestão de alimentos ricos em creatina e creatinina e a produção endógena dela, pelo músculo esquelético. Além disso, é influenciado pelo estado catabólico, função renal residual e condição de hidratação. A qualidade da massa muscular parece ser mais importante do que a sua quantidade. A avaliação da força e da função muscular possibilitam a identificação precoce de perda de massa corporal. A força muscular pode ser medida de forma direta, por meio da dinamometria. Esta pode incluir testes de força de preensão palmar e, também, de pinçamento dos dedos. Estudo com pacientes de HD demonstrou que as forças de pinçamento dos dedos e de preensão palmar tiveram alta correlação entre si, mas o pinçamento foi mais conveniente e fácil de executar durante sessão de $\mathrm{HD}^{28}$. $\mathrm{O}$ KDOQI/Academy ${ }^{16}$ sugere a medida da força de preensão palmar como indicador de desnutrição e condição funcional de pacientes com DRC G1-5D, mas ainda necessita de medidas prévias para comparação. Metanálise revelou associação entre força de preensão palmar baixa e mortalidade de todas as causas em pacientes em diálise ${ }^{29}$. Estudo de pacientes em HD e DP demonstrou correlação entre força de preensão palmar e mortalidade quando os cortes foram de $22,5 \mathrm{~kg}$ para homens e de $7 \mathrm{~kg}$ para mulheres ${ }^{30}$. Outros indicadores de força e capacidade de exercício físico em pacientes com DRC, como velocidade de marcha e atividades de vida diária (AVD), também foram associados com mortalidade $^{31,32}$. A qualidade de vida é um indicador que engloba força e capacidade de exercício, e também está associada com estado nutricional. Em relação à obesidade, a gordura abdominal, mais do que o IMC, identifica risco cardiovascular. A circunferência da cintura (CC) é sugerida pelo KDOQI/Academy ${ }^{16}$, com observação de que a confiabilidade para mudanças ao longo do tempo é baixa. O índice de conicidade (IC), ou taxa da circunferência da cintura/ estatura, é mais sensível do que a CC e o IMC para detectar risco cardiovascular e de doenças crônicas ${ }^{33}$. O KDOQI/ Academy ${ }^{16}$ sugere o IC como preditor de mortalidade para adultos com DRC 5D em HD.

\section{Questão 3: Há instrumentos de diagnóstico de desnutrição específicos para pacientes com doença renal?}

\section{Recomendação 3: O instrumento recomendado para diagnosticar desnutrição é a SGA (Subjective Global Assessment) tradicional.}

\section{Nível de evidência: Moderado}

A avaliação do estado nutricional de pacientes com doença renal deve utilizar a combinação de dados da história, achados físicos, medidas antropométricas, bioquímicos, testes e procedimentos clínicos relacionados à nutrição. Especificamente para o diagnóstico de desnutrição, grande número de instrumentos tem sido propostos e validados para pacientes com DRC. A SGA é um instrumento clássico e foi validada diversas vezes em todos os estágios da DRC. Além disso, a SGA tradicional deu origem a diversos outros instrumentos, como a Avaliação Subjetiva Global Pontuada Gerada pelo Paciente (Patient Generated - SGA, PG-SGA), a SGA de Sete Pontos e o Escore de Desnutrição-Inflamação (MalnutritionInflammation Score, MIS). Todos foram associados com mortalidade em pacientes com DRC. O KDOQI/Academy $2020^{16}$ recomenda a SGA de Sete Pontos para pacientes com DRC em estágio 5 e sugere a MIS para pacientes em HD e pós TR. Entretanto, por serem específicos para pacientes com DRC, a SGA de Sete Pontos e a MIS não atendem ao critério de universalidade, buscado atualmente. Um instrumento promissor para o objetivo é a MCC (Malnutrition Clinical Characteristics - Características Clínicas da Desnutrição). Este utiliza três categorias de desnutrição baseada na etiologia para cada indicador, e não inclui o índice de massa corporal (IMC) ou a albumina sérica, o que é apoiado pelo KDOQI/ Academy ${ }^{16}$. Dois dos seguintes indicadores diagnosticam a desnutrição: redução da ingestão energética, perda de peso, perda de gordura corporal, perda de massa muscular, acúmulo de líquido e redução da força de preensão palmar. A MCC teve acurácia satisfatória e concordância moderada, comparada à SGA, quando aplicada em adultos hospitalizados graves em geral, em trauma ou cirúrgicos. Em relação a desfechos, a MCC foi capaz de prever maiores tempo e custos de hospitalização. A desnutrição, avaliada pela MCC, foi associada à mortalidade em longo prazo (até dois anos) em idosos com pneumonia ${ }^{34}$. Em pacientes de unidade de terapia intensiva (UTI), a MCC foi preditora de morte e de tempo de internação ${ }^{35,36}$. Estudo recente validou a MCC para 
pacientes enfermos críticos, com boa especificidade, sensibilidade, precisão, valor preditivo positivo e valor preditivo negativo ${ }^{37}$. Neste, a MCC identificou mais pacientes com desnutrição grave, em comparação à SGA. Em outra coorte prospectiva de adultos e idosos, a MCC, comparada à SGA e mesmo sem inclusão da força de preensão palmar, apresentou validade concorrente e preditiva, boa concordância e acurácia satisfatória para tempo de hospitalização, morte hospitalar e após seis de alta, e para taxa de readmissão ${ }^{38}$. A vantagem da $M C C$, em relação à SGA, é a objetividade do instrumento. De acordo com KDOQI/Academy ${ }^{16}$, a avaliação em nutrição para adultos com DRC G3-5D ou pós TR deve ser aplicada dentro de 90 dias do início de diálise, anualmente, ou quando indicada pela triagem de risco nutricional ou por referência. Entretanto, devido aos riscos para desnutrição, à falta de conhecimento em relação aos cuidados e às alterações metabólicas que podem ser minimizadas, é produtivo recomendar a avaliação em nutrição dentro do primeiro mês de início da diálise e mensalmente, a partir disso. Pacientes com DRC G4-5 ou pós-TR devem ser avaliados, pelo menos, a cada três meses, e aqueles com DRC G1-3, a cada seis meses ${ }^{16}$.

\section{INJÚRIA RENAL AGUDA}

\section{Questão 4 - Qual é a recomendação de ener- gia para pacientes graves com IRA?}

Recomendação 4: A recomendação de energia para pacientes com IRA é $20-30 \mathrm{kcal} / \mathrm{kg} / \mathrm{dia}$ de peso seco ou ideal (em caso de obesidade ou muito baixo peso). A nutrição hipocalórica ( $<70 \%$ do gasto energético) é recomendada na fase inicial da enfermidade aguda, com aumento progressivo após o terceiro dia, nos pacientes em recuperação.

\section{Nível de evidência: Moderado}

A IRA grave está correlacionada ao hipermetabolismo e hipercatabolismo, associados a sepse, choque, trauma e cirurgia de grande porte. Estudo avaliou o gasto energético de repouso (GER) por calorimetria indireta (Cl), em 68 adultos com sepse em ventilação mecânica, com e sem IRA, dentro de 72 h após diagnóstico de sepse e sete dias após o primeiro exame $^{39}$. Não houve diferenças significativas no GER entre os grupos. Outra investigação com $\mathrm{Cl}$ não demonstrou diferença na variação diária em 301 medidas do GER de 114 pacientes com IRA e ventilação mecânica, medido no dia da indicação de HD e durante os quatro dias subsequentes ${ }^{40}$. $O$ GER teve correlação positiva com peso corporal, volume-minuto e fração inspirada de oxigênio na ventilação mecânica, e negativa com a idade. Uma coorte prospectiva avaliou o GER por $\mathrm{Cl}$ de 100 pacientes, antes e durante diferentes modalidades de diálise intermitente (HD convencional, HD estendida e DP de alto volume ${ }^{41}$. Não foram observadas diferenças significativas entre GER pré-dialítico e durante a diálise, nas diferentes modalidades. Em estudo, a estimativa do GER por Cl de 125 pacientes com IRA G3 foi comparada a nove equações preditivas, e nenhuma apresentou acurácia ${ }^{42}$. A maioria subestimou o gasto energético. $\bigcirc$ mesmo resultado foi demonstrado em outro estudo de pacientes de UTI com IRA ${ }^{43}$. A recomendação de energia de pacientes com IRA é de 20-30 kcal $/ \mathrm{kg} / \mathrm{dia}$. Quanto mais grave, menor é o aporte recomendado. A nutrição hipocalórica, que não exceda $70 \%$ do gasto energético, é indicada na fase inicial da enfermidade $^{44}$. Depois de, aproximadamente, três ou quatro dias, a oferta pode ser progressivamente aumentada para $80 \%$ a $100 \%$ do gasto energético total estimado. As TRRC podem ser fontes significativas de energia, que devem ser subtraídas do aporte total, calculado para o paciente. Fluidos de reposição/ diálise podem conter de 0-110 mg/dL de glicose. Quando sem glicose, podem contribuir para perda de glicose pelo efluente, enquanto fluidos com glicose tem impacto mínimo em ganho ou perda de glicose pelo efluente. $O$ anticoagulante citrato também é fonte de calorias: citrato trissódico $4 \%$ (3 kcal $/ \mathrm{g})$ e soluções do tipo ACD-A, que contêm citrato $2,2 \%$ (3 kcal $/ \mathrm{g})$ e glicose 2,45\% $(3,4 \mathrm{kcal} / \mathrm{g})^{4}$. Além disso, soro glicosado e emulsões lipídicas podem ser usados para administrar medicamentos, e devem ser considerados no aporte total de energia para esses pacientes, com objetivo de evitar a hiperalimentação.

\section{Questão 5 - Qual é a recomendação de prote- ínas para pacientes com IRA?}

\begin{abstract}
Recomendação 5: A recomendação de proteínas para pacientes hipercatabólicos com IRA e sem TRR é de 1,3-1,5 g/ $\mathrm{kg} /$ dia. Em TRR intermitente, a recomendação é de cerca de $1,5 \mathrm{~g} / \mathrm{kg} / \mathrm{dia}$. Em TRR contínua, deve ser de 1,7-2,5 g/ kg/dia. Proteínas não devem ser restringidas para pacientes hipercatabólicos com objetivo de evitar ou retardar o início de TRR. Porém, pode ser controlada para aqueles não hipercatabólicos e sem necessidade de TRR, com recomendação em torno de 0,8-1,0 g/ $\mathrm{kg} /$ dia.
\end{abstract}

\section{Nível de evidência: Baixo}

Pacientes com IRA apresentam diferentes graus de catabolismo, alto risco de desnutrição, que está associada ao aumento da mortalidade. Estudo prospectivo observacional, com 199 pacientes críticos com câncer e IRA, recebendo 
DBES, demonstrou que a sobrevida foi melhor quando os balanços nitrogenados estavam mais positivos ${ }^{45}$. Porém, ainda não está claro quais são as doses recomendadas de proteínas que podem contribuir melhor para a sobrevida ou recuperação renal. Estudo prospectivo e multicêntrico de pacientes graves com IRA comparou a determinação da necessidade de proteínas por meio de equações ou por taxa de catabolismo proteico, enquanto em nutrição enteral ou parenteral ${ }^{43}$. A média de necessidade medida foi de $1,3 \mathrm{~g} / \mathrm{kg}$ de peso atual para pacientes sem TRR. As equações apresentam grande variação (recomendações mínimas e máximas), que pode levar a erros na estimativa. Mas pacientes com alto grau de catabolismo geralmente têm indicação de TRR. Grande estudo randomizado post hoc, com 1.457 pacientes, não demonstrou redução de desfechos clínicos com o aporte proteico, mas a média de oferta foi de, somente, $0,5 \mathrm{~g} / \mathrm{kg} / \mathrm{dia}^{46}$. Estudos prospectivos antigos, com pacientes em TRRC, revelaram balanço nitrogenado menos negativo com ofertas proteicas de 1,5-1,8 $\mathrm{g} / \mathrm{kg} / \mathrm{dia}^{47,48}$. Pacientes com IRA em TRRC perdem em torno de 10 a $15 \mathrm{~g} /$ dia de aminoácidos, embora os estudos sejam pequenos e antigos, de tempos com diferenças nas práticas clínicas ${ }^{44}$. As perdas dependem do tipo da TRRC (convecção ou difusão), taxa de fluxo sanguíneo, taxa de fluxo de diálise, taxa do efluente e propriedades da membrana do filtro 4 . A perda em 24 horas é maior $30 \%$ a $40 \%$ ) em TRRC por convecção do que por difusão ${ }^{4}$. A recomendação de proteínas para pacientes hipercatabólicos com IRA sem TRR é 1,3-1,5 g/ kg/dia, com iniciação gradual até a meta (três a cinco dias) ${ }^{44}$. Em caso de TRR intermitente, a recomendação é de cerca de $1,5 \mathrm{~g} / \mathrm{kg} /$ dia. Se em TRRC, é recomendado de 1,7 até $2,5 \mathrm{~g} / \mathrm{kg} / \mathrm{dia}^{49}$. A recomendação de tais doses são reforçadas pelo argumento de que não aumentam, significativamente, os níveis de ureia sérica ou promovem perdas desproporcionais de aminoácidos ${ }^{4}$. Já para os pacientes com IRA com baixo grau de catabolismo e sem TRR, a recomendação exata de proteínas é incerta, e ainda necessita de mais pesquisas de boa qualidade. Concorda-se que não é indicada grande restrição ${ }^{49,50}$. A sugestão é de $0,8-1,0 \mathrm{~g} / \mathrm{kg} / \mathrm{dia}$, ou até menos, dependendo do estado nutricional e da causa da $I^{2} A^{51}$. Vale ressaltar a importância de ingestão adequada de energia $(30 \mathrm{kcal} / \mathrm{kg} / \mathrm{dia})$

\section{Questão 6 - A suplementação de glutamina é indicada para pacientes com IRA?}

\author{
Recomendação 6: A suplementação de glutamina \\ não é indicada para pacientes hipercatabólicos com \\ IRA.
}

Nível de evidência: Baixo
Glutamina é um aminoácido não essencial que é importante fonte de energia para células de proliferação rápida como linfócitos e enterócitos. Além disso, também é substrato hepático para neoglicogênese. O metabolismo de glutamina gera amônia. Com isso, a suplementação de glutamina pode aumentar, rapidamente, níveis de amônia sérica. Portanto, para pacientes instáveis e complexos, particularmente aqueles com alteração hepática ou renal, a glutamina via parenteral não é recomendada ${ }^{52}$. A suplementação dela tem sido recomendada, apenas, por via enteral em queimaduras e em traumas ${ }^{53,54}$. Metanálise com estudos randomizados e controlados de pacientes adultos críticos revelou que a suplementação de glutamina via parenteral, entre $0,3-0,5 \mathrm{~g} / \mathrm{kg} / \mathrm{dia}$, melhorou o prognóstico ${ }^{55}$. No entanto, a investigação excluiu pacientes com doenças hepáticas e renais. Já o REDOX, estudo multicêntrico, demonstrou que a suplementação precoce de glutamina, particularmente em doses elevadas, teve relação com aumento da mortalidade de pacientes com IRA ${ }^{56}$. Portanto, até que novos estudos demonstrem segurança em relação à dose, a suplementação de glutamina via enteral ou parenteral não é recomendada para esses pacientes.

\section{Questão 7 - Quando é recomendada a suple- mentação de micronutrientes na IRA?}

\section{Recomendação 7: A suplementação de micronu- trientes é recomendada para pacientes com IRA em TRR.}

\section{Nível de evidência: Baixo}

As necessidades de vitaminas e de oligoelementos de pacientes com IRA dependem do grau de catabolismo, da fase da doença, do volume urinário, da presença de perdas por fístulas, drenos, sondas, feridas, queimaduras e outros, e do tempo de jejum ou desnutrição prévia. Também dependem do tipo, da frequência e da duração das TRR. Estudo demonstrou que as perdas de micronutrientes são maiores na HFVVC do que na HDFVVC e na HD ${ }^{57}$. Porém, a recomendação de micronutrientes ainda não está clara, pelo fato de ausência de estudos controlados que definam as necessidades específicas e/ou mostrem desfechos após suplementação. Frequentemente, os níveis séricos de oligoelementos estão anormais ${ }^{58}$. Porém, estudo não mostrou diferença no zinco, selênio e cobre, medidos nos três primeiros dias de TRR ${ }^{59}$. Já outro estudo prospectivo encontrou concentrações séricas abaixo do desejável de vitamina $D_{3}$, vitamina $C$, selênio, zinco e ferro durante seis 
dias de TRR ${ }^{60}$. A vitamina $C$ pode ser protetora de dano renal oxidativo e para a função vascular. A recomendação é de 60-100 mg/dia ${ }^{16}$. O excesso pode elevar o risco de oxalose secundária. As demais vitaminas hidrossolúveis são recomendadas de acordo com as Recommended Dietary Intakes (RDAs). Para a vitamina $A$, também há risco de acúmulo e de toxicidade. Se suplementada, deve haver monitoramento cuidadoso dos níveis séricos.

\section{Questão 8 - Como deve ser o manejo de ele- trólitos de pacientes com IRA?}

Recomendação 8: O manejo de eletrólitos de pacientes com IRA deve ser individualizado, de acordo com os níveis séricos. A necessidade de reposição depende de resultados séricos de cada paciente e de cada eletrólito. Níveis elevados podem indicar TRR.

\section{Nível de evidência: Moderado}

A IRA resulta em alterações importantes na homeostasia de cátions (sódio, potássio, cálcio e magnésio) e de ânions (cloreto e bicarbonato). Quando os níveis estão elevados, a TRR pode ser indicada. Entretanto, o procedimento também pode promover distúrbios significativos nos eletrólitos $^{61}$. Estudo de coorte com 13.621 pacientes com IRA em UTI demonstrou que os níveis séricos de sódio e potássio na admissão foram associados com sobrevida com curva em formato de $U^{62}$. A hiponatremia e a hipernatremia, assim como a hipocalemia e a hipercalemia, foram associadas com aumento de mortalidade. Além disso, a hipercalemia foi associada com aumento da mortalidade em 90 dias naqueles que tiveram hiponatremia. Já quando ao contrário, a hipernatremia foi sutil nos efeitos prognósticos do potássio. Níveis baixos de cálcio ionizado na admissão também foram preditores independentes de mortalidade de todas as causas, conforme mostrado em estudo epidemiológico com 10.207 pacientes de UTI com IRA ${ }^{63}$. Além disso, os níveis séricos de cloreto e de bicarbonato estão relacionados com desfechos na IRA ${ }^{64}$. A hipofosfatemia é comum em pacientes em IRA com TRR contínuas, e pode causar fraqueza muscular generalizada, disfunção do miocárdio e dificuldade de desmame do respirador. Estudo retrospectivo revelou incidência de 59\% de hipofosfatemia induzida pela TRR e recomendou suplementação de $2 \mathrm{mmol} / \mathrm{L}$ de fosfato, embora diferentes concentrações possam ser necessárias ${ }^{65}$. Portanto, o manejo de eletrólitos deve ser realizado a partir do monitoramento frequente e cuidados, e a conduta deve ser tomada de acordo com a necessidade individual.

\section{Questão 9 - Que tipos de formulações de nutri- ção enteral (NE) e de nutrição parenteral (NP) são indicadas para pacientes com IRA?}

Recomendação 9: Formulações padrão de nutrição enteral e/ou parenteral são recomendadas para pacientes hipercatabólicos com IRA e/ou em TRR. Formulações com restrição de eletrólitos podem ser indicadas de acordo com a necessidade individual.

\section{Nível de evidência: Baixo}

A IRA altera o metabolismo e excreção de líquidos, de metabólitos e de micronutrientes. Além disso, durante a TRR, há perdas significativas de aminoácidos e de eletrólitos, que variam de acordo com a modalidade ${ }^{57}$. $O$ hipercatabolismo na IRA é causado, principalmente, por: 1) perdas de nutrientes no dialisato, em caso de TRR, 2) inflamação, 3) acidose metabólica, 4) hiperinsulinemia, 5) intolerância à glicose, e 6) presença de enfermidades associadas. Até o momento, não há estudo controlado, prospectivo e homogêneo em humanos que tenha comparado resultados do uso de diferentes formulações de nutrição enteral e/ou parenteral em pacientes com IRA, com ou sem TRR. Aminoácidos, como a tirosina, a cisteína e a histidina, são condicionalmente essenciais em situações de hipercatabolismo. Por isso, são recomendadas formulações que contenham aminoácidos padrão (mistura de essenciais e não essenciais) e ricas em proteína para pacientes hipercatabólicos com IRA, tanto para nutrição enteral como para a parenteral ${ }^{49,66}$. Devido ao risco de acúmulo de líquidos na IRA, formulações com densidade calórica mais elevada (por exemplo, 1,5-2,0 kcal/mL) são preferidas. A indicação de formulações especializadas de TNE e/ou TNP com redução na quantidade de eletrólitos, como potássio, fósforo e sódio, é individual e dependente dos níveis séricos do momento, de cada paciente.

\section{DOENÇA RENAL CRÔNICA}

\section{Questão 10 - Qual é a recomendação de ener- gia para pacientes com DRC?}

Recomendação 10: A recomendação de energia é de 25-35 $\mathrm{kcal} / \mathrm{kg} /$ dia para pacientes metabolicamente estáveis, baseado na idade, sexo, atividade física, estado nutricional, estágio da DRC e comorbidades associadas.

Nível de evidência: Baixo 
Não há muitos estudos sobre gasto energético de pacientes com DRC. Além do sexo e da idade, há diversos fatores que podem alterar as necessidades de energia, como massa muscular, função da tireoide, inflamação, diabetes e hiperparatireoidismo. Por exemplo, o aumento do gasto energético pode ser mascarado pela baixa atividade física e massa muscular reduzida. Em caso de obesidade, a recomendação de energia pode ser mais baixa por quilograma de peso, para manter o peso corporal, pelo fato de a gordura corporal ser metabolicamente menos ativa. Por outro lado, pacientes hipercatabólicos podem necessitar de mais energia. O consenso concluiu que o gasto energético, medido por $\mathrm{Cl}$, é semelhante ou menor em pacientes com DRC do que em indivíduos saudáveis e, para obesidade, a recomendação de $35 \mathrm{kcal} / \mathrm{kg} /$ dia pode superestimar o gasto energético ${ }^{67}$. As equações de Harris \& Benedict e Schofield parecem superestimar as necessidades ${ }^{68}$. Uma importante lacuna é a ausência de estudos comparativos sobre qual peso corporal usar (ideal, atual, ajustado para obesidade) nas equações de estimativa de gasto energético para pacientes com DRC. O KDOQI/Academy $2020^{16}$ recomenda $25-35 \mathrm{kcal} / \mathrm{kg} / \mathrm{dia}$ para que sejam contemplados os diversos fatores que podem influenciar o gasto energético e as necessidades de ajustes em caso de desnutrição ou obesidade.

\section{Questão 11 - Qual é a recomendação de pro- teínas para pacientes com DRC G3-5 e com DRC 5D?}

\begin{abstract}
Recomendação 11: A recomendação de proteínas para adultos com DRC 3-5 é de 0,6-0,8 g/ kg/dia, com aporte energético adequado. A variação mais baixa é recomendada para preservação da função renal de pacientes sem risco nutricional. A taxa mais elevada tem o mesmo objetivo, mas contempla a necessidade daqueles com diabetes mellitus, desnutrição, idade avançada e/ou outras condições de risco. Para adultos com DRC G5D, em HD ou DP, a recomendação proteica é de $1,2 \mathrm{~g} / \mathrm{kg} /$ dia, com ingestão energética adequada.
\end{abstract}

\section{Nível de evidência: Moderado}

Para pacientes com DRC G3-5, há dois princípios fisiológicos que embasam controle na ingestão proteica: 1) redução de acúmulo de toxinas urêmicas, que pode evitar sinais clínicos e retardar o início de diálise; 2) redução de hiperfiltração renal e de fibrose intersticial, que pode retardar a queda da TFG. Porém, no momento, há dificuldade para definir a quantidade ideal de proteínas para pacientes com DRC G3-5. A razão é a falta de uniformidade nos protocolos de estudos em relação às quantidades ofertadas de proteínas, aos estágios e etiologias da DRC, e à avaliação da adesão à ingestão prescrita. Houve benefício em relação à morte/ início de diálise quando comparada oferta proteica de 0,6 $\mathrm{g} / \mathrm{kg} /$ dia versus ingestão habitual em diferentes estágios de DRC ${ }^{69}$. Porém, em outro estudo, para pacientes com DRC G4-5, não houve benefício entre 0,55 versus $0,8 \mathrm{~g} / \mathrm{kg} /$ dia $^{70}$. Além disso, estudos randomizados não demonstraram diferença em relação à redução da queda da TFG entre ofertas de 0,55-0,6 versus $0,8 \mathrm{~g} / \mathrm{kg} / \mathrm{dia}^{69-73}$. A restrição em torno de $0,6 \mathrm{~g} / \mathrm{kg} /$ dia de proteínas foi demonstrada segura $^{71}$. Porém, a maioria dos estudos excluiu pacientes desnutridos e utilizou somente medidas antropométricas e albumina sérica como indicadores de estado nutricional. Por outro lado, há estudos que revelaram redução discreta, mas significativa, da massa muscular, embora não avaliados força e funcionalidade ${ }^{74,75}$. Outra particularidade em relação à restrição proteica é o paciente idoso com redução leve da TFG e com baixa probabilidade de progressão. Estes podem não se beneficiar de restrição proteica ${ }^{76}$. Conforme demonstrado em metanálise de 13 estudos randomizados, com 1.919 pacientes, a velocidade de redução do declínio da TFG com restrição proteica foi de $0,53 \mathrm{~mL} / \mathrm{min} / \mathrm{ano}^{77}$. Portanto, restrição proteica rigorosa pode não ser racional para indivíduos com idade avançada. Entende-se, atualmente, que a ingestão proteica pode influenciar diretamente na microbiota intestinal de pacientes com DRC, e promover progressão da doença e piora do risco cardiovascular ${ }^{78}$. Porém, ainda não há resultados em relação a quantidades específicas relacionadas à disbiose. Em suma, o grau de restrição de proteína não deve ser baseado, somente, na TFG. Deve considerar fatores múltiplos, como idade, estado nutricional e funcional, velocidade de progressão da DRC, sobrevida do paciente versus prognóstico renal, impacto da dieta no controle de outras comorbidades e viabilidade de monitoramento da nutrição. Além disso, deve considerar o desejo do indivíduo, após ter sido informado sobre potenciais benefícios e dificuldades da restrição proteica. O KDOQI/ Academy ${ }^{16}$ recomenda $0,55-0,60 \mathrm{~g} / \mathrm{kg}$ de peso por dia ou metade desta quantidade, com suplementação de cetoanálogos. Porém, para pacientes com diabetes, que apresentam risco mais alto de desnutrição, recomenda 0,6-0,8 g/ $\mathrm{kg}$ de peso por $\mathrm{dia}^{16}$. Portanto, para contemplar as necessidades, inclusive de risco de desnutrição e presença de diabetes, pode ser recomendada a variação de 0,6-0,8 g/ $\mathrm{kg}$ de peso, para pacientes com DRC G3-5. Para indivíduos hipercatabólicos, como aqueles com internação hospitalar recente, doenças infecciosas ou inflamatórias ativas, neoplasias e perda de peso recente significativa ${ }^{16}$, a restrição proteica não é recomendada, pois a baixa ingestão está associada a altas taxas de hospitalização e risco de mortalidade ${ }^{79}$. Já em caso da terapia dialítica não ser opção ou necessitar ser 
postergada (maturação de acesso vascular, organização de transplante preemptivo), a restrição proteica é indicada ${ }^{16}$. Para pacientes com DRC G5D, há perdas de aminoácidos e proteínas durante procedimentos dialíticos, dificuldades de síntese de novas proteínas e hipercatabolismo proteico muscular, devido a acidose metabólica, processos inflamatórios e outros fatores. Portanto, a necessidade proteica é maior do que aquela de indivíduos saudáveis. A recomendação é de $1,2 \mathrm{~g} / \mathrm{kg}$ de peso por dia para pacientes em HD, inclusive para diabetes ${ }^{16}$. Porém, a necessidade pode ser mais elevada, dependendo do nível de estresse e de alterações metabólicas. Além disso, quantidades mais altas de proteínas podem ser indicadas para manter controle glicêmico, em caso de hiperglicemia ou hipoglicemia ${ }^{16}$.

\section{Questão 12 - Qual é o papel da dieta hipopro- teica suplementada com cetoanálogos na DRC?}

Recomendação 12: A dieta com, aproximadamente, $0,3-0,4 \mathrm{~g} / \mathrm{kg} /$ dia de proteína suplementada com cetoanálogos, ou aminoácidos essenciais, para pacientes com DRC G4-5 diminui o risco de falência renal, reduz proteinúria, e pode ter efeitos benéficos sobre complicações metabólicas, sem causar prejuízos no estado nutricional.

\section{Nível de evidência: Moderado/alto}

Os cetoanálogos são análogos de aminoácidos essenciais sem o radical nitrogênio. Em teoria, a reação de transaminação pode incorporar o nitrogênio disponível e formar o aminoácido correspondente. Assim, ao mesmo tempo que supre a necessidade de aminoácidos essenciais na dieta muito restrita em proteínas, os cetoanálogos poderiam promover diminuição do excesso de nitrogênio e reduzir carga de compostos nitrogenados tóxicos. Segundo a diretriz KDOQI/Academy $2020^{16}$, a dieta com cerca de 0,3-0,4 $\mathrm{g} / \mathrm{kg} /$ dia de proteína suplementada com cetoanálogos é recomendada, para reduzir o risco de falência renal. Revisão sistemática com metanálise que incluiu 17 ensaios clínicos randomizados controlados, totalizando 1.400 pacientes com DRC sem TRR, revelou que a dieta muito restrita em proteínas e suplementada com cetoanálogos apresenta benefícios em vários desfechos clínicos ${ }^{80}$. Salientou-se a preservação da taxa de filtração glomerular, redução da proteinúria, além de melhora de marcadores de complicações, como acidose, resistência à insulina e distúrbios do metabolismo mineral e ósseo. Resultados semelhantes foram encontrados em revisão narrativa recente ${ }^{81}$. Para que se obtenham resultados satisfatórios, sem risco de desnutrição, essa dieta deve ser prescrita para pacientes sem diabetes, que estejam metabolicamente estáveis, acompanhados frequentemente e, principalmente, motivados para boa adesão ao tratamento ${ }^{82}$.

\section{Questão 13 - As proteínas vegetais são reco- mendadas na dieta de pacientes com DRC?}

\begin{abstract}
Recomendação 13: Embora as proteínas de origem vegetal possam ter ação biológica positiva e possível benefício clínico para pacientes com DRC, as evidências são insuficientes para recomendar a substituição de proteínas animais por vegetais. Efeitos benéficos podem estar associados náo somente ao tipo de proteína, mas ao padrão dietético, baseado em maior proporção de alimentos de origem vegetal.
\end{abstract}

\section{Nível de evidência: Muito baixo}

Há algumas evidências sobre proteínas provenientes de alimentos de origem vegetal exercerem efeito mais baixo sobre a filtração glomerular, comparadas às de animal. Isso poderia evitar ou minimizar a hiperfiltração glomerular e suas respectivas consequências, com retardo no ritmo de progressão da DRC. Porém, os poucos estudos clínicos que avaliaram o impacto de dietas com proteínas de origem vegetal na DRC apresentaram resultados inconclusivos ${ }^{82}$. Não foram observadas diferenças na função renal quando dieta hipoproteica foi feita à base de proteína vegetal (principalmente soja) ou de animal. Ambas resultaram em retardo no ritmo de progressão da doença e diminuição da proteinúria ${ }^{83-85}$. Portanto, o benefício parece ser devido, principalmente, à menor ingestão proteica, independentemente da origem. No entanto, a dieta à base de proteínas vegetais pode propiciar outros benefícios para pacientes com DRC, como menos carga ácida, gorduras saturadas e fósforo biodisponível. Porém, apenas estudos observacionais e poucos controlados, de curta duração e com pequeno número de pacientes, mostraram efeitos potenciais ${ }^{86,87}$. Atualmente, há grande número de artigos de revisão para pacientes com DRC que sugerem benefícios potenciais, não somente do tipo de proteína (vegetal vs. animal), mas especialmente de padrão dietético baseado em alimentos de vegetal ${ }^{88}$. Ainda são necessários estudos de intervenção para concluir riscos e benefícios para pacientes com DRC.

\section{Questão 14 - Quais são as recomendações para controle de fósforo, potássio e sódio?}

Recomendação 14: Para pacientes adultos com DRC G3-5D, a ingestão alimentar de fósforo deve ser ajustada para manter os níveis séricos do mineral dentro da normalidade. Restrição deve ser indicada 
na presença de hiperfosfatemia persistente e progressiva, e após a avaliação, também, de níveis séricos de cálcio e PTH. A intervenção em nutrição deve considerar não somente a quantidade de fósforo, mas suas fontes dietéticas e a presença de aditivos em alimentos processados. A ingestão alimentar de potássio, de forma prudente, deve ser ajustada para manter seus níveis séricos dentro da normalidade. A ingestão alimentar de sódio é recomendada em $<2,3 \mathrm{~g} /$ dia, em conjunto com intervenções farmacológicas aplicáveis.

\section{Nível de evidência: Moderado (fósforo e sódio) e opinião de especialista (potássio)}

equilíbrio fisiológico do fósforo sérico depende, em conjunto, da absorção intestinal dele na dieta, da filtração glomerular e da excreção e reabsorção tubular no rim, assim como do equilíbrio entre a formação e reabsorção óssea ${ }^{89}$. A hiperfosfatemia é, normalmente, observada quando a TFG está abaixo de $45 \mathrm{~mL} / \mathrm{min}^{2}$. Mas há escassez de estudos bem desenhados sobre a relação entre níveis séricos de fósforo com a ingestão alimentar. Por isso, o KDOQI/Academy ${ }^{16}$ não define quantidades, mas recomenda ajustes na ingestão alimentar de fósforo para manter os níveis séricos do mineral nas variações normais. Também sugere que, quando houver indicação de restrição de fósforo, é razoável considerar a biodisponibilidade das fontes (por exemplo, animal, vegetal, de aditivos). A recomendação é que a ingestão deve ser ajustada para manter os níveis séricos normais dele. Desta forma, a recomendação é individualizada, e deve considerar a ingestão alimentar, particularmente com escolha de alimentos que contenham menos fósforo inorgânico, que tem absorção intestinal mais alta. Os alimentos processados, que contêm aditivos de fosfato (fósforo inorgânico), tendem a apresentar valor nutricional mais baixo e, muitas vezes, são ricos em sódio e em aditivos de potássio. A forma de preparação (método de cozimento) também pode influenciar significativamente no teor de fósforo dos alimentos ${ }^{16}$. Para pacientes em diálise, com recomendação de dietas mais ricas em proteína, uma estratégia para restrição de fósforo é selecionar fontes alimentares com taxa fósforo/proteína baixa (por exemplo, clara de ovo, carnes) e evitar laticínios.

Embora seja indicado manter os níveis de potássio sérico dentro da faixa de normalidade, alterações são comuns em pacientes com DRC, particularmente naqueles com distúrbios tubulares e TFG baixa ${ }^{90}$. No momento, as evidências são escassas em relação ao efeito da restrição da ingestão alimentar nos níveis séricos do mineral ${ }^{16}$. Há estudos que demonstraram associação fraca entre eles ${ }^{90-93}$. No assunto, é essencial compreender que diversos fatores, além da ingestão alimentar, podem influenciar o potássio sérico, entre eles, o uso de certos medicamentos, a função renal residual, os estados de hidratação e acidobásico, glicemia, função adrenal, estado catabólico e problemas gastrointestinais, como vômitos, diarreia, constipação e sangramento ${ }^{91-93}$. Todos devem ser avaliados antes de recomendar restrições de alimentos ricos em potássio. Estes incluem frutas e hortaliças que, por outro lado, são boas fontes fibras e micronutrientes ${ }^{16,90}$. Quando há indicação de restrição, um aspecto primário é evitar alimentos ultraprocessados que contêm aditivos de potássio. $\bigcirc$ potássio dos aditivos pode aumentar o teor do mineral nos alimentos em $20 \%{ }^{90}$.

O sódio é o cátion extracelular responsável pelo equilíbrio dos fluidos corporais. Entretanto, com a progressão da DRC, o balanço pode ser comprometido com a ingestão excessiva e/ou excreção inadequada dele. Estudos mostraram melhores resultados no controle da pressão arterial e na excreção de sódio em pacientes com DRC G3-594,95 e G5D ${ }^{96}$ com dietas com restrição do mineral. Embora geralmente recomendado 2-2,3 g/dia para pacientes com DRC G3-5D, não há consenso sobre o que significa ingestão elevada de sódio ${ }^{16,94}$ 96. A recomendação deve ser individualizada e ajustada para pressão arterial, TFG, estado de hidratação e GPID, presença de acidose, glicemia, grau de catabolismo e perdas, como gastrointestinais (vômitos e diarreia).

\section{Questão 15 - Quais são as recomendações para ganho de peso interdialítico (GPID) e controle hídrico?}

\author{
Recomendação 15: O GPID recomendado em HD \\ é de $2-4 \%$ do peso corporal seco. A ingestão diária \\ recomendada de líquidos depende do GPID.
}

\section{Nível de evidência: Moderado}

Para pacientes em HD, o GPID deficiente ou excessivo está relacionado com aumento do risco de morbidade e mortalidade. Em coorte prospectivo, com mais de 17 mil pacientes, o GPID foi associado com risco relativo de morte de todas as causas ${ }^{23}$. O GPID recomendado foi entre 2-4\% do peso seco do paciente. Não há estudos controlados que definam a quantidade recomendada de ingestão de líquidos para alcançar o GPID adequado. Porém, o volume de excreção urinária é bom indicador para a recomendação. $\bigcirc$ GPID deficiente tem relação com ingestão alimentar baixa e desnutrição. Portanto, pode ser bom indicador de risco nutricional. Por outro lado, grande número de pacientes em HD têm GPID acima do recomendado97. O problema tem efeitos negativos nos desfechos cardiovasculares, na qualidade de vida e nos custos de saúde, já que pode exigir mais cuidados e tempo de diálise. $\bigcirc$ excesso de GPID tem relação com a 
ingestão elevada de sódio e de líquido. Pacientes com função renal residual têm mais facilidade para controlar o GPID. As consequências diretas da retirada de excesso de GPID na diálise são a sede e a xerostomia ${ }^{97}$. A sede tem relação com osmolaridade sérica alta, devido à ingestão elevada de sódio e pela própria uremia. A sede ocorre, geralmente, após a sessão de HD, e segue por horas após, devido à perda de água e sódio durante o procedimento. Além do controle na ingestão de sódio e líquido, outra estratégia para controle do GPID é a seleção de dialisato com concentração mais baixa de sódio ${ }^{97}$.

\section{Questão 16 - A suplementação de vitaminas e oligoelementos é indicada na rotina de pa- cientes com DRC?}

Recomendação 16: A ingestão alimentar de pacientes com DRC G3-5D deve suprir a necessidade de vitaminas e oligoelementos da mesma forma que para a população saudável. A suplementação individualizada é indicada quando a avaliação ou monitoramento em nutrição indicarem risco ou presença de deficiência. Pacientes DRC G5D apresentam perdas durante o procedimento dialítico e podem necessitar de suplementação quando a ingestão alimentar estiver insuficiente por períodos longos de tempo. Vitaminas lipossolúveis devem ser suplementadas somente em caso de deficiência.

\section{Nível de evidência: Baixo}

Há algumas evidências que indicam que pacientes com DRC podem apresentar deficiência em certos micronutrientes. As razões são múltiplas, como ingestão alimentar subótima ou desequilibrada, prescrições dietéticas que limitam fontes alimentares, perda durante procedimentos dialíticos, absorção ineficiente, uso de certos medicamentos e alteração do metabolismo, em decorrência da própria DRC ${ }^{16,98}$. Porém, ainda não há evidências suficientes que indiquem benefício ou prejuízo da suplementação rotineira para esses pacientes $^{99-101}$, e a maioria dos estudos foi realizado em HD contínua. Obviamente, indivíduos desnutridos e aqueles com ingestão deficiente têm indicação de suplementação de vitaminas e minerais. Em certas situações, concomitantes à DRC, há aumento do risco de deficiência, como gestação, idade avançada, cirurgia de bypass gástrico, anorexia, má absorção, vegetarianos e em uso certos medicamentos ${ }^{16}$. Para adultos com DRC G1-5D, o KDOQI/Academy $2020^{16}$ recomenda suplementar folato, vitamina $B_{12}$ e/ou complexo $B$ para corrigir deficiência/insuficiência, com base em sinais e sintomas $\operatorname{clínicos}^{16}$. Mas sugere a não suplementação rotineira de folato ou de todo o complexo B como tratamento da hiperhomocisteinemia, pois não há evidências que demonstrem redução de desfechos cardiovasculares. As mesmas diretrizes não recomendam suplementação rotineira de selênio ou zinco, pelo fato de haver pouca evidência de benefício para o estado nutricional ou inflamatório. Quando indicada, a suplementação deve estar de acordo com as quantidades recomendadas para a população saudável (RDA), exceto em casos específicos ${ }^{16}$. Em deficiência/ insuficiência de $25(\mathrm{OH})$ vitamina $\mathrm{D}$, a suplementação é recomendada na forma de colecalciferol ou ergocalciferol ${ }^{16}$. Vitaminas lipossoluveis, como A e $E$, não têm indicação de suplementação rotineira, devido ao risco de toxicidade. Pacientes que recebem medicamentos anticoagulantes, que inibem a atividade da vitamina $\mathrm{K}$ (por exemplo, varfarina), não têm indicação de suplementação desta vitamina ${ }^{16}$. $O$ ideal é que os suplementos sejam adaptados às necessidades individuais de vitaminas e oligoelementos, para evitar doses excessivas $^{16}$.

\section{Questão 17 - Quando indicar suplemento nu- tricional oral (SNO)? E quais as características?}

Recomendação 17: SNO é recomendado quando a ingestão somente com a dieta não alcança as necessidades de energia e proteína, e há risco ou presença de desnutrição. Formulações padrão de SNO são recomendadas, exceto em casos de alterações metabólicas que exijam ajustes na composição química.

\section{Nível de evidência: Baixo}

A oferta de alimentos e nutrientes, juntamente com educação e aconselhamento em nutrição, devem priorizar a via oral. Quando há necessidade de reforço, os SNO são indicados. $\mathrm{KDOQ} /$ Academy $^{16}$ recomenda tentativas de, no mínimo, três meses com SNO para pacientes em qualquer fase da DRC que estejam em risco ou em desnutrição, caso o aconselhamento baseado em alimentos não tenha sido suficiente para alcançar as necessidades de energia e proteínas. Os SNO podem ser industrializados ou artesanais (elaborados a partir de alimentos). A composição/característica ideal e a frequência de uso de SNO ainda não estão definidas. Quando não há alterações metabólicas graves, e o aporte com SNO não ultrapassar 20-25\% da necessidade total do paciente, formulações não especializadas podem ser indicadas. Já no caso de o paciente apresentar alterações metabólicas (por exemplo, hipercalemia, hiperfosfatemia), são recomendadas formulações especializadas. Na escolha do SNO, é essencial considerar o aporte de energia e proteínas como parte da oferta planejada ao paciente. A 
maior limitação do uso de SNO é a baixa adesão e/ou a descontinuação. Efeitos colaterais gastrintestinais podem influenciar na adesão. Portanto, a exploração de características, como sabor, cheiro, aparência, textura e versatilidade, pode auxiliar na aceitabilidade ${ }^{16}$. Os pacientes podem ser aconselhados a não substituir refeições por SNO e usá-los, preferencialmente, duas a três vezes ao dia, uma hora após as refeições. Uma estratégia tem sido o fornecimento de SNO durante as sessões de HD. O Consenso da Sociedade Internacional de Nutrição e Metabolismo Renal ${ }^{102}$ diz que a oferta de alimentos, refeições e lanches e/ou SNO durante a HD deve ser considerada, para melhorar o estado nutricional dos pacientes. Porém, conclui que há necessidade de estudos randomizados para estabelecer benefícios. Estudo comparou 1.420 pacientes com uso de SNO intradialítico com outros 1.571 indivíduos em HD que não o utilizaram, durante 30 dias pós-hospitalização, observando diminuição significativa na taxa de readmissão com uso do $\mathrm{SNO}^{103}$. Porém, o estudo comparou o uso de SNO ou nenhuma adição de energia e nutrientes, e não a comparação dele usado em momentos diferentes do dia (por exemplo, em domicílio ou intradialítico). A ingestão durante a sessão de HD ainda apresenta controvérsias, pois pode resultar em hipotensão, que está relacionada a riscos e mortalidade desses pacientes ${ }^{104}$. Além disso, alimentos ou líquidos ingeridos durante a diálise podem aumentar o risco de engasgos e broncoaspiração, e necessitam de cuidados especiais ${ }^{102}$.

\section{Questão 18 - Quando indicar a nutrição ente- ral (NE)? Há necessidade de formulações es- pecializadas?}

\begin{abstract}
Recomendação 18: A nutrição enteral (NE) é indicada para pacientes adultos com DRC G3-5D quando a ingestão oral (dieta e SNO) estiver insuficiente para alcançar as necessidades de energia e nutrientes, e exista risco ou presença de desnutrição. Formulações especializadas podem ser indicadas de acordo com necessidades individuais do paciente.
\end{abstract}

\section{Nível de evidência: Baixo}

A NE é indicada quando não houve sucesso na manutenção ou recuperação do estado nutricional somente com a via oral, e presença de anorexia, confusão mental, letargia, coma e outros. Porém, estudos sobre NE por sonda em adultos com DRC têm pequena casuística e são observacionais ${ }^{105,106}$. $O \mathrm{KDOQI} /$ Academy $^{16}$ recomenda tentativa de NE para os pacientes com ingestão alimentar cronicamente subótima, quando a via oral com alimentos e SNO não conseguiu alcançar as necessidades. Critérios de indicação podem ser as comorbidades, o estado geral e as perspectivas de sobrevida ${ }^{107}$. Em relação ao tipo de formulações, os reais benefícios de especializadas para pacientes com DRC ainda são inconclusivos. O tipo depende do aporte necessário, da quantidade ingerida de alimentos e da condição metabólica do paciente. Formulações especializadas para pacientes com DRC G5HD podem ser preferidas, pois permitem aporte energético e de nutrientes com redução de eletrólitos (sódio, potássio e fósforo) e maior densidade calórica (favorece o balanço hídrico), comparadas às padrões ${ }^{108}$.

\section{Questão 19 - Quando há indicação de nutrição parenteral intradialítica (NPID)?}

\section{Recomendação 19: A NPID é indicada para pacien- tes em HD quando a ingestão da dieta e SNO não alcança as necessidades de energia e nutrientes, e há risco ou presença de desnutrição.}

\section{Nível de evidência: Baixo}

Para pacientes em HD, a NPID é uma opção para complementar o aporte nutricional, particularmente quando não há adesão ao uso de SNO ou perda parcial da capacidade de absorção de nutrientes, em risco ou presença de desnutrição. $O$ KDOQI/Academy $2020^{16}$ recomenda tentativa com NPID para pacientes em HD, quando as necessidades nutricionais não foram alcançadas com a via oral ou sonda. Revisão sistemática de 12 estudos demonstrou semelhança em desfechos clínicos, quando comparados a NPID, o aconselhamento em nutrição e os $\mathrm{SNO}^{109}$. O FineS é estudo prospectivo e randomizado, que comparou o uso isolado de SNO ou associado à NPID, em 186 pacientes em HD durante um ano ${ }^{110}$. Após dois anos, não houve diferença nas taxas de sobrevida e de hospitalização, no IMC, nos níveis séricos de albumina e pré-albumina, e nos resultados do índice de Karnofsky, entre os grupos. A maior limitação do estudo, entretanto, foi a interrupção das intervenções após um ano e análise de desfechos, como mortalidade, após dois anos. Ou seja, dificilmente uma terapia nutricional teria efeito residual para esse tempo, especialmente se em pacientes em HD. Outro estudo prospectivo, multicêntrico e randomizado comparou a intervenção padrão de nutrição via oral com a mesma terapia, mas com adição da NPID ${ }^{11}$. A duração foi de 16 semanas, com acompanhamento sem tratamento por mais 12 semanas. Foram estudados 107 pacientes em HD com desnutrição moderada a grave. $\bigcirc$ grupo com NPID apresentou melhora significativa nos níveis séricos de préalbumina, que foi mantida no período de acompanhamento. A resposta foi mais evidente nos pacientes com desnutrição 
moderada do que grave. Volumes de um litro de NPID são bem tolerados por sessão e as formulações podem ser individualizadas em quantidades de glicose, aminoácidos, lipídeos, vitaminas, oligoelementos e eletrólitos específicos. As vantagens da NIPD incluem a não necessidade de instalação de acesso venoso e a ultrafiltração na terapia dialítica, que evita a sobrecarga hídrica recebida pela infusão. A NPID oferece segurança para o paciente, pois é realizada durante a diálise, com assistência profissional especializada. As perdas de nutrientes durante a HD parecem ser menores com a NPID, mas a interação de nutrientes com a membrana dialítica ainda não está clara ${ }^{5}$. Embora não deva ser indicada para substituir a via oral ou em caso de necessidade de NP total, sob o ponto de vista metabólico e nutricional, a NPID pode ser considerada eficiente para controlar o hipercatabolismo do procedimento de HD. Três vezes por semana, a NPID pode ofertar quantidades de nutrientes semelhantes ao uso diário de SNO. O aporte é em torno de $1.000 \mathrm{kcal}$ e $50-60 \mathrm{~g}$ de aminoácidos cada vez, aproximadamente $3.000 \mathrm{kcal}$ e $150-180 \mathrm{~g}$ de aminoácidos por semana. Uma vantagem da NPID é a taxa de retenção de nutrientes via parenteral, que é quase de 100\%, comparada à intestinal, que é em torno de $60 \%$.

\section{SITUAÇÕES ESPECIAIS}

\section{Questão 20 - Quais são as recomendações de energia e proteínas para gestantes com DRC?}

\begin{abstract}
Recomendação 20: A recomendação de energia para gestantes com DRC G1-5 é de $35 \mathrm{kcal} / \mathrm{kg} / \mathrm{dia}$, com uso do peso pré-gestacional. Devem ser acrescentadas $85 \mathrm{kcal} /$ dia, no primeiro, $275 \mathrm{kcal} / \mathrm{dia}$, no segundo, e $475 \mathrm{kcal} /$ dia, no terceiro trimestre de gestação. Para gestantes com DRC G5 em HD, a recomendação é de $25-35 \mathrm{kcal} / \mathrm{kg} / \mathrm{dia}$, e em DP, é de $25 \mathrm{kcal} / \mathrm{kg} /$ dia. A recomendação de proteína para gestantes com DRC G1-2 é semelhante às mulheres saudáveis. Para DRC G3-4, a recomendação é de 0,6-0,8 g/ kg/dia, com 6-10 g adicionais de proteína, aminoácidos ou cetoanálogos. Para pacientes com DRC 5D, a recomendação é de $1,2 \mathrm{~g} / \mathrm{kg} / \mathrm{dia}$, para $H D$, e $1,4 \mathrm{~g} / \mathrm{kg} /$ dia, para $D P$.
\end{abstract}

\section{Nível de evidência: Baixo}

Mulheres com DRC G3-5D têm dificuldade de engravidar, sobretudo devido a irregularidades no ciclo menstrual e anovulação, causadas por desregulação no eixo hipotalâmico-hipofisário-gonadal. Porém, a prevalência de gestantes com DRC tem aumentado nos últimos anos, e o manejo das complicações tem sido mais bem-sucedido ${ }^{112}$. As principais complicações materno-fetais são hipertensão gestacional, polidrâmnio, crescimento intrauterino restrito, prematuridade e pré-eclâmpsia ${ }^{113}$. Há escassez de estudos em relação às recomendações energéticas para essa população. A recomendação é mais alta em DRC G1-5 e semelhante às gestantes saudáveis, de $35 \mathrm{kcal} /$ $\mathrm{kg} /$ dia (utilizado peso pré-gestacional), com acréscimo de 85,275 e $475 \mathrm{kcal} /$ dia no primeiro, segundo e terceiro trimestre, respectivamente 114,115 . De forma mais simples, podem ser adicionados $300 \mathrm{kcal} /$ dia a partir do segundo trimestre de gestação ${ }^{114}$. Para gestantes com DRC 5D em $H D$, a recomendação é a mesma que para não gestantes na mesma modalidade dialítica $(25-35 \mathrm{kcal} / \mathrm{kg} / \mathrm{dia})$. Em DP, a recomendação energética é mais baixa, em torno de $25 \mathrm{kcal} / \mathrm{kg} /$ dia, devido ao aporte diário de glicose do líquido peritoneal ${ }^{114}$. Em relação a proteínas para gestantes com DRC G1-2, há falta de estudos comparativos, e a recomendação tem sido semelhante às saudáveis. Para aquelas com DRC G3-5, baseado em poucos estudos ${ }^{116,117}$, parece seguro recomendar controle proteico moderado de $0,6-0,8 \mathrm{~g} / \mathrm{kg} /$ dia com fontes vegetais, suplementado com cetoanálogos (1 comprimido para cada $8-10 \mathrm{~kg}$ ), 6-10 g/ dia de aminoácidos essenciais ou de proteína ${ }^{115}$. Gestantes com DRC G5D têm recomendação de diálise intensiva, para manter a ureia sérica em torno de $100 \mathrm{mg} / \mathrm{dL}^{114}$. Neste caso, há melhor controle hídrico, de pressão arterial e de metabólitos, e a dieta pode ser mais liberal. Por outro lado, há aumento de perdas de aminoácidos ou proteínas, vitaminas hidrossolúveis e alguns minerais, durante o procedimento dialítico. Baseado, também, em escassos estudos, a recomendação de proteínas para gestantes com DRC G5D em HD é em torno de 1,2 g/ $\mathrm{kg} /$ dia e para DP, em torno de 1,4 g/kg de peso pré-gestacional ${ }^{114,115}$. A partir da falta de estudos controlados, as recomendações de energia e nutrientes devem ser individualizadas, considerando peso pré-gestação, ganho de peso gestacional, e estado nutricional e metabólico durante todo o período.

\section{Questão 21 - Quais são as recomendações de energia e de proteínas para crianças e adoles- centes com DRC?}

Recomendação 21: As recomendações de energia e proteínas para crianças com DRC G2-5 são semelhantes àquelas saudáveis, para a idade cronológica, mas no limite mais alto recomendado. Não é recomendada restrição proteica para crianças e adolescentes com DRC 3-5D.

\section{Nível de evidência: Baixo}


O objetivo principal das recomendações de energia e proteínas em pediatria é assegurar a curva de crescimento e o ganho de peso adequados. Baseado em alguns estudos com calorimetria indireta, a Força Tarefa em Nutrição Renal Pediátrica concluiu que as recomendações de energia para crianças e adolescentes com DRC G2-5D são semelhantes às saudáveis, nas mesmas idades cronológicas ${ }^{118}$. Ajustes na recomendação devem ser feitos com base em taxas de ganho ou perda de peso. Para crianças em DP, deve ser considerada a energia absorvida pela glicose do dialisato. Um ponto de destaque é o aumento da incidência de obesidade, também em crianças e adolescentes com DRC. Estudo demonstrou que o consumo de energia e proteínas de crianças com DRC foi maior do que o recomendado ${ }^{119}$. Porém, ajustes na recomendação energética e proteica de crianças com DRC já obesas devem ser cuidadosos, para evitar comprometimento do estado nutricional e crescimento. Estudos são escassos em relação às necessidades de proteínas em qualquer fase da DRC de crianças e adolescentes. A Força Tarefa recomenda a taxa máxima das RDA para crianças e adolescentes com DRC G3-5D, devido às perdas de aminoácidos ou proteínas durante diálise, alteração na síntese proteica e necessidade de crescimento ${ }^{118}$. Portanto, mesmo para crianças e adolescentes com DRC G3-5, não é recomendada restrição da ingestão proteica. $\bigcirc$ mínimo recomendado, se monitorado cuidadosamente, é a taxa mais baixa recomendada (RDA) para crianças e adolescentes saudáveis, na mesma idade cronológica. Para bebês com DRC 3-5D, o aleitamento materno exclusivo também é recomendado até seis meses de vida. Quando este não é possível ou não é suficiente, são recomendadas fórmulas com proteína do soro do leite, que podem ser fortificadas com módulos de nutrientes, quando houver necessidade de aumento da densidade calórica ou de adição de algum nutriente específico ${ }^{118}$.

\section{Questão 22 - Quais são as recomendações de energia e de proteínas para idosos com DRC?}

Recomendação 22: A recomendação de energia para
idosos com DRC é de $25-35 \mathrm{kcal} / \mathrm{kg} /$ dia, e a de pro-
teínas para aqueles com DRC G4-5 é de $0,6-0,8 \mathrm{~g} /$
$\mathrm{kg} /$ dia. A dieta muito baixa em proteína $(0,3 \mathrm{~g} / \mathrm{kg} /$
dia), associada à suplementação com cetoanálogos,
parece segura. A recomendaçáo proteica para idosos
com DRC G5D, em HD ou DP, é de $1,2-1,5 \mathrm{~g} / \mathrm{kg} /$ dia.

\section{Nível de evidência: Moderado}

O idoso com DRC tem risco mais elevado de desenvolver síndrome de fragilidade, comparado ao saudável. A síndrome caracteriza-se pela perda de peso não intencional, exaustão, lentidão ao caminhar e redução da funcionalidade. Esta ocorre devido a inúmeros fatores, com destaque à associação da sarcopenia e hiporexia. Outros fatores contribuintes são sobrecarga hídrica, TRR, uremia, redução dos níveis de testosterona e de vitamina $D$, uso de certos medicamentos, aumento da produção de citocinas inflamatórias e acidose metabólica. A síndrome de fragilidade pode acometer até $11 \%$ dos pacientes geriátricos com DRC ${ }^{120}$. Portanto, além da adequação às necessidades de energia, proteínas e outros nutrientes, o objetivo da terapia nutricional de pacientes idosos com DRC é melhorar a funcionalidade, a reabilitação e a qualidade de vida. As recomendações devem ser individualizadas, com base, principalmente, no estádio da DRC, estado nutricional e funcionalidade. Não há estudos que tenham comparado a necessidade energética de pacientes idosos sem e com DRC. Portanto, as recomendações são genéricas, de 25 a $35 \mathrm{kcal} / \mathrm{kg} /$ dia. Da mesma forma, há escassez de estudos comparativos, prospectivos e randomizados que tenham identificado as necessidades de proteínas de idosos com DRC. O grupo PROT-AGE faz recomendações de acordo com a TFG, com associação de exercícios aeróbicos e resistidos ${ }^{76}$. A quantidade recomendada de proteínas foi $0,8 \mathrm{~g} / \mathrm{kg} /$ dia quando a TFG é menor de $30 \mathrm{~mL} / \mathrm{min}$ e para idosos com DRC G5D, tanto HD como DP, a recomendação foi de 1,2-1,5 g/kg/dia. Idosos com DRC G4-5 sem diabetes podem ter recomendação proteica de 0,6-0,8 g/ $\mathrm{kg} /$ dia. Embora também não haja estudos comparativos, a dieta muito baixa proteína com suplementação de cetoanálogos parece segura. Em pacientes idosos com DRC G5D, a recomendação de 1,2-1,5 g/ $/ \mathrm{kg} /$ dia de proteína parece razoável. No momento, não há evidências suficientemente robustas para indicar ingestão de proteínas vegetais isoladas.

\section{Questão 23 - Quais são as recomendações de energia e proteínas para pacientes com TR?}

\begin{abstract}
Recomendação 23: A recomendação de energia e nutrientes depende do período do TR. A recomendação média de energia é de $25-35 \mathrm{kcal} / \mathrm{kg} /$ dia. No TR imediato e em caso de rejeição aguda do enxerto, a recomendação de proteínas é de 1,3-1,5 g/ $\mathrm{kg}$ de peso atual ou ideal. No pós-TR tardio, a recomendação é em torno de $0,8 \mathrm{~g} / \mathrm{kg} / \mathrm{dia}$. A restrição de 0,6 $\mathrm{g} / \mathrm{kg} /$ dia pode ser considerada em caso de rejeição crônica.
\end{abstract}

\section{Nível de evidência: Moderado}

As recomendações de energia e nutrientes devem estar adequadas às fases do TR: pré, pós imediato (em torno de 4-6 semanas) e pós-tardio. No pós-TR imediato, há 
catabolismo proteico intenso, principalmente devido ao estresse da cirurgia e ao uso de doses altas de medicamentos imunossupressores. A desnutrição pode aumentar a taxa de morbidade e mortalidade pós-cirúrgica. No período pós-TR tardio, a terapia imunossupressora está associada a múltiplos efeitos colaterais em longo prazo, que incluem: hipercatabolismo proteico, obesidade, dislipidemia, intolerância à glicose, hipertensão, hipercalemia e alteração no metabolismo e ação da vitamina D. A obesidade pode aumentar significativamente a morbidade e a mortalidade do enxerto renal e do paciente. A recomendação média de energia para pacientes com TR é de $25-35 \mathrm{kcal} / \mathrm{kg}$ de peso atual ou ideal por dia, baseado em: idade, sexo, nível de atividade, composição corporal, objetivos de peso corporal e presença de enfermidade associada ou inflamação ${ }^{16}$. A recomendação no TR imediato é em torno de $30-35 \mathrm{kcal} /$ $\mathrm{kg} /$ dia, com foco em manutenção do peso. Já no TR tardio, a recomendação é de $25-35 \mathrm{kcal} / \mathrm{kg} /$ dia. Em caso de risco ou presença de obesidade, a recomendação é de $20-25 \mathrm{kcal} /$ $\mathrm{kg} / \mathrm{dia}$, com exercício físico regular concomitante. A dieta mediterrânea é sugerida pelo KDOQI/Academy ${ }^{16}$. Estudo com 632 receptores de TR, acompanhados por 5,4 anos (média), mostrou que aqueles aderentes à dieta mediterrânea tiveram resultado inverso em relação à perda da função renal e do enxerto ${ }^{121}$. Para proteínas, a recomendação no pós-TR imediato, e se houver rejeição aguda do enxerto, é de 1,3-1,5 g/kg de peso atual ou ideal. A recomendação serve, também, para pacientes que necessitam de HD ou DP por algum tempo, após o TR. No TR tardio, a recomendação de proteínas é a mesma da RDA, em torno de $0,8 \mathrm{~g} / \mathrm{kg} /$ dia. A restrição proteica de $0,6 \mathrm{~g} / \mathrm{kg} /$ dia pode ser considerada em caso de função renal anormal (rejeição crônica), quando a TFG estiver abaixo de $45 \mathrm{~mL} / \mathrm{min} / 1,73 \mathrm{~m}^{2}{ }^{122}$, desde que 0 aporte calórico esteja adequado.

\section{REFERÊNCIAS}

1. Guyatt GH, Oxman AD, Vist GE, Kunz R, Falck-Ytter Y, AlonsoCoello P, et al; GRADE Working Group. GRADE: an emerging consensus on rating quality of evidence and strength of recommendations. BMJ. 2008;336(7650):924-6.

2. Levey AS, Eckardt KU, Dorman NM, Christiansen SL, Hoorn EJ, Ingelfinger JR, et al. Nomenclature for kidney function and disease: report of a Kidney Disease: Improving Global Outcomes (KDIGO) Consensus Conference. Kidney Int. 2020;97(6):1117-29.

3. MercadoMG, SmithDK, GuardEL.Acutekidneyinjury: diagnosis and management. Am Fam Physician. 2019;100(11):687-94.

4. Nystrom EM, Nei AM. Metabolic support of the patient on continuous renal replacement therapy. Nutr Clin Pract. 2018;33(6):754-66.

5. Piccoli GB, Lippi F, Fois A, Gendrot L, Nielsen L, Vigreux J, et al. Intradialytic nutrition and hemodialysis prescriptions: a personalized stepwise approach. Nutrients. 2020;12(3):785.

6. Koppe L, Fouque D, Kalantar-Zadeh K. Kidney cachexia or protein-energy wasting in chronic kidney disease: facts and numbers. J Cachexia Sarcopenia Muscle. 2019;10(3):479-84.
7. Yu Z, Grams ME, Ndumele CE, Wagenknecht L, Boerwinkle E, North KE, et al. Association between midlife obesity and kidney function trajectories: the Atherosclerosis Risk in Communities (ARIC) Study. Am J Kidney Dis. 2021;77(3):376-85.

8. Yun HR, Kim H, Park JT, Chang TI, Yoo TH, Kang SW, et al; Korean Cohort Study for Outcomes in Patients With Chronic Kidney Disease (KNOW-CKD) Investigators. Obesity, metabolic abnormality, and progression of CKD. Am J Kidney Dis. 2018;72(3):400-10.

9. Lin TY, Liu JS, Hung SC. Obesity and risk of end-stage renal disease in patients with chronic kidney disease: a cohort study. Am J Clin Nutr. 2018;108(5):1145-53.

10. Doshi M, Streja E, Rhee CM, Park J, Ravel VA, Soohoo M, et al. Examining the robustness of the obesity paradox in maintenance hemodialysis patients: a marginal structural model analysis. Nephrol Dial Transplant. 2016;31(8):1310-9.

11. Park JM, Lee JH, Jang HM, Park Y, Kim YS, Kang SW, et al; Clinical Research Center for End Stage Renal Disease (CRC for ESRD) Investigators. Survival in patients on hemodialysis: effect of gender according to body mass index and creatinine. PLoS One. 2018;13(5):e0196550.

12. Ziolkowski SL, Long J, Baker JF, Chertow GM, Leonard MB. Chronic kidney disease and the adiposity paradox: valid or confounded? J Ren Nutr. 2019;29(6):521-8.

13. Paudel K, Visser A, Burke S, Samad N, Fan SL. Can bioimpedance measurements of lean and fat tissue mass replace Subjective Global Assessments in peritoneal dialysis patients? J Ren Nutr. 2015;25(6):480-7.

14. Obi Y, Streja E, Mehrotra R, Rivara MB, Rhee CM, Soohoo M, et al. Impact of obesity on modality longevity, residual kidney function, peritonitis, and survival among incident peritoneal dialysis patients. Am J Kidney Dis. 2018;71(6):802-13.

15. Castro ACM, Bazanelli AP, Nerbass FB, Cuppari L, Kamimura MA. Waist circumference as a predictor of mortality in peritoneal dialysis patients: a follow-up study of 48 months. Br J Nutr. 2017;117(9):1299-303.

16. Ikizler TA, Burrowes JD, Byham-Gray LD, Campbell KL, Carrero JJ, Chan W, et al. KDOQI clinical practice guideline for nutrition in CKD: 2020 update. Am J Kidney Dis. 2020;76(3 Suppl 1):S1-S

17. Skipper A, Coltman A, Tomesko J, Charney P, Porcari J, Piemonte TA, et al. Adult malnutrition (undernutrition) screening: an evidence analysis center systematic review. J Acad Nutr Diet. 2020;120(4):669-708.

18. Lawson CS, Campbell KL, Dimakopoulos I, Dockrell ME. Assessing the validity and reliability of the MUST and MST nutrition screening tools in renal inpatients. J Ren Nutr. 2012;22(5):499-506.

19. Di Bella A, Croisier E, Blake C, Pelecanos A, Bauer J, Brown $\mathrm{T}$. Assessing the concurrent validity and interrater reliability of patient-led screening using the malnutrition screening tool in the ambulatory cancer care outpatient setting. J Acad Nutr Diet. 2020;120(7):1210-5.

20. Marshall S, Young A, Bauer J, Isenring E. Nutrition screening in geriatric rehabilitation: criterion (concurrent and predictive) validity of the Malnutrition Screening Tool and the Mini Nutritional Assessment-Short Form. J Acad Nutr Diet. 2016;116(5):795-801.

21. Kang SS, Chang JW, Park Y. Nutritional status predicts 10 -year mortality in patients with end-stage renal disease on hemodialysis. Nutrients. 2017;9(4):399.

22. Eriguchi R, Obi Y, Streja E, Tortorici AR, Rhee CM, Soohoo M, et al. Longitudinal associations among renal urea clearancecorrected normalized protein catabolic rate, serum albumin, and mortality in patients on hemodialysis. Clin J Am Soc Nephrol. 2017;12(7):1109-17.

23. Wong MM, McCullough KP, Bieber BA, Bommer J, Hecking $\mathrm{M}$, Levin NW, et al. Interdialytic weight gain: trends, predictors, and associated outcomes in the International Dialysis 
Outcomes and Practice Patterns Study (DOPPS). Am J Kidney Dis. 2017;69(3):367-79.

24. Dubey AK, Priyamvada PS, Sahoo J, Vairappan B, Haridasan S, Parameswaran S. Reliability of anthropometry-based equations compared to dual energy absorptiometry for assessing body composition in predialysis chronic kidney disease: a longitudinal study. J Ren Nutr. 2020;30(3):216-22.

25. Mulasi U, Kuchnia AJ, Cole AJ, Earthman CP. Bioimpedance at the bedside: current applications, limitations, and opportunities. Nutr Clin Pract. 2015;30(2):180-93.

26. Shin JH, Kim CR, Park KH, Hwang JH, Kim SH. Predicting clinical outcomes using phase angle as assessed by bioelectrical impedance analysis in maintenance hemodialysis patients. Nutrition. 2017;41:7-13.

27. Huang R, Wu M, Wu H, Ye H, Peng Y, Yi C, et al. Lower phase angle measured by bioelectrical impedance analysis is a marker for increased mortality in incident continuous ambulatory peritoneal dialysis patients. J Ren Nutr. 2020;30(2):119-25.

28. El-Katab S, Omichi Y, Srivareerat M, Davenport A. Pinch grip strength as an alternative assessment to hand grip strength for assessing muscle strength in patients with chronic kidney disease treated by haemodialysis: a prospective audit. J Hum Nutr Diet. 2016;29(1):48-51.

29. Hwang SH, Lee DH, Min J, Jeon JY. Handgrip strength as a predictor of all-cause mortality in patients with chronic kidney disease undergoing dialysis: a meta-analysis of prospective cohort studies. J Ren Nutr. 2019;29(6):471-9.

30. Vogt BP, Borges MCC, Goés CR, Caramori JCT. Handgrip strength is an independent predictor of all-cause mortality in maintenance dialysis patients. Clin Nutr. 2016;35(6):1429-33.

31. Watson EL, Major RW, Wilkinson TJ, Greening NJ, Gould DW, Barratt J, et al. The association of muscle size, strength and exercise capacity with all-cause mortality in non-dialysis-dependent CKD patients. Clin Physiol Funct Imaging. 2020;40(6):399-406.

32. Morishita S, Tsubaki A, Shirai N. Physical function was related to mortality in patients with chronic kidney disease and dialysis. Hemodial Int. 2017;21(4):483-9.

33. Ashwell M, Gunn P, Gibson S. Waist-to-height ratio is a better screening tool than waist circumference and BMI for adult cardiometabolic risk factors: a systematic review and metaanalysis. Obes Rev. 2012;13(3):275-86.

34. Yeo HJ, Byun KS, Han J, Kim JH, Lee SE, Yoon SH, et al. Prognostic significance of malnutrition for long-term mortality in community-acquired pneumonia: a propensity score matched analysis. Korean J Intern Med. 2019;34(4):841-9.

35. Ceniccola GD, Holanda TP, Pequeno RSF, Mendonça VS, Oliveira ABM, Carvalho LSF, et al. Relevance of AND-ASPEN criteria of malnutrition to predict hospital mortality in critically ill patients: a prospective study. J Crit Care. 2018;44:398-403.

36. Hiura G, Lebwohl B, Seres DS. Malnutrition diagnosis in critically ill patients using 2012 Academy of Nutrition and Dietetics/ American Society for Parenteral and Enteral Nutrition standardized diagnostic characteristics is associated with longer hospital and intensive care unit length of stay and increased in-hospital mortality. JPEN J Parenter Enteral Nutr. 2020;44(2):256-64.

37. Vavruk AM, Martins C, Mazza do Nascimento M. Validation of Malnutrition Clinical Characteristics in critically ill patients. Nutr Clin Pract. 2021. doi: 10.1002/ncp.10637.

38. Burgel CF, Teixeira PP, Leites GM, Carvalho GD, Modanese PVG, Rabito EI, et al. Concurrent and predictive validity of AND-ASPEN Malnutrition Consensus is satisfactory in hospitalized patients: a longitudinal study. JPEN J Parenter Enteral Nutr. 2020. doi: 10.1002/jpen.1980.

39. Sanches ACS, Goes CR, Berbel MN, Balbi AL, Ponce D. Does acute kidney injury alter energy metabolism of septic patients? Arch Ren Dis Manag. 2016;2:19-23.

40. Góes CR, Sanches AC, Balbi A, Ponce D. Daily variability of resting energy expenditure in acute kidney injury patients on dialysis. J Bras Nefrol. 2017;39(1):15-22.
41. Góes CR, Vogt BP, Sanches ACS, Balbi AL, Ponce D. Influence of different dialysis modalities in the measurement of resting energy expenditure in patients with acute kidney injury in ICU. Clin Nutr. 2017;36(4):1170-4.

42. Góes CR, Berbel-Bufarah MN, Sanches AC, Xavier PS, Balbi AL, Ponce D. Poor agreement between predictive equations of energy expenditure and measured energy expenditure in critically ill acute kidney injury patients. Ann Nutr Metab. 2016;68(4):276-84.

43. Sabatino A, Theilla M, Hellerman M, Singer P, Maggiore U, Barbagallo M, et al. Energy and protein in critically ill patients with AKI: a prospective, multicenter observational study using indirect calorimetry and protein catabolic rate. Nutrients. 2017;9(8):802.

44. Ostermann M, Macedo E, Oudemans-van Straaten H. How to feed a patient with acute kidney injury. Intensive Care Med. 2019;45(7):1006-8.

45. Salahudeen AK, Kumar V, Madan N, Xiao L, Lahoti A, Samuels $\mathrm{J}$, et al. Sustained low efficiency dialysis in the continuous mode (C-SLED): dialysis efficacy, clinical outcomes, and survival predictors in critically ill cancer patients. Clin J Am Soc Nephrol. 2009;4(8):1338-46.

46. Bellomo R, Cass A, Cole L, Finfer S, Gallagher M, Lee J, et al. Daily protein intake and patient outcomes in severe acute kidney injury: findings of the randomized evaluation of normal versus augmented level of replacement therapy (RENAL) trial. Blood Purif. 2014;37(4):325-34.

47. Macias WL, Alaka KJ, Murphy MH, Miller ME, Clark WR, Mueller BA. Impact of the nutritional regimen on protein catabolism and nitrogen balance in patients with acute renal failure. JPEN J Parenter Enteral Nutr. 1996;20(1):56-62.

48. Bellomo R, Seacombe J, Daskalakis M, Farmer M, Wright C, Parkin $\mathrm{G}$, et al. A prospective comparative study of moderate versus high protein intake for critically ill patients with acute renal failure. Ren Fail. 1997;19(1):111-20.

49. McClave SA, Taylor BE, Martindale RG, Warren MM, Johnson DR, Braunschweig C, et al; Society of Critical Care Medicine; American Society for Parenteral and Enteral Nutrition. Guidelines for the provision and assessment of nutrition support therapy in the adult critically ill patient: Society of Critical Care Medicine (SCCM) and American Society for Parenteral and Enteral Nutrition (A.S.P.E.N.). JPEN J Parenter Enteral Nutr. 2016;40(2):159-211.

50. Schwartz E, Hillyer R, Foley J, Willcutts K, Ziegler J. Acute kidney injury masked by malnutrition: a case report and the problem of protein. Nutr Clin Pract. 2019;34(5):735-50.

51. Kidney Disease: Improving Global Outcomes (KDIGO) Acute Kidney Injury Work Group. KDIGO Clinical Practice Guideline for Acute Kidney Injury. Kidney Int Suppl. 2012;2:1-138.

52. Singer P, Blaser AR, Berger MM, Alhazzani W, Calder PC, Casaer MP, et al. ESPEN guideline on clinical nutrition in the intensive care unit. Clin Nutr. 2019;38(1):48-79.

53. Wischmeyer PE. The glutamine debate in surgery and critical care. Curr Opin Crit Care. 2019;25(4):322-8.

54. Castro MG, Ribeiro PC, Souza IAO, Cunha HFR, Silva MHN, Rocha EEM, et al. Diretriz brasileira de terapia nutricional no paciente grave. BRASPEN J. 2018;33(Supl 1):2-36.

55. Stehle P, Ellger B, Kojic D, Feuersenger A, Schneid C, Stover J, et al. Glutamine dipeptide-supplemented parenteral nutrition improves the clinical outcomes of critically ill patients: a systematic evaluation of randomised controlled trials. Clin Nutr ESPEN. 2017; 17:75-85.

56. Heyland D, Muscedere J, Wischmeyer PE, Cook D, Jones G, Albert M, et al; Canadian Critical Care Trials Group. A randomized trial of glutamine and antioxidants in critically ill patients. N Engl J Med. 2013;368(16):1489-97.

57. Oh WC, Mafrici B, Rigby M, Harvey D, Sharman A, Allen $\mathrm{JC}$, et al. Micronutrient and amino acid losses during renal 
replacement therapy for acute kidney injury. Kidney Int Rep. 2019;4(8):1094-108.

58. Leaf DE, Christov M. Dysregulated mineral metabolism in AKI. Semin Nephrol. 2019;39(1):41-56.

59. Kritmetapak K, Peerapornratana S, Srisawat N, Somlaw N, Lakananurak N, Dissayabutra T, et al. The impact of macro-and micronutrients on predicting outcomes of critically ill patients requiring continuous renal replacement therapy. PLoS One. 2016;11(6): 0156634.

60. Ostermann M, Summers J, Lei K, Card D, Harrington DJ, Sherwood R, et al. Micronutrients in critically ill patients with severe acute kidney injury: a prospective study. Sci Rep. 2020;10(1):1505.

61. Jung SY, Kim H, Park S, Jhee JH, Yun HR, Kim H, et al. Electrolyte and mineral disturbances in septic acute kidney injury patients undergoing continuous renal replacement therapy. Medicine (Baltimore). 2016;95(36):e4542.

62. Gao XP, Zheng CF, Liao MQ, He H, Liu YH, Jing CX, et al. Admission serum sodium and potassium levels predict survival among critically ill patients with acute kidney injury: a cohort study. BMC Nephrol. 2019;20(1):311.

63. Wang B, Li D, Gong Y, Ying B, Cheng B. Association of serum total and ionized calcium with all-cause mortality incritically ill patients with acute kidney injury. Clin Chim Acta. 2019;494:94-9.

64. Rein JL, Coca SG. "I don't get no respect": the role of chloride in acute kidney injury. Am J Physiol Renal Physiol. 2019;316(3):F587-F605.

65. Song YH, Seo EH, Yoo YS, Jo YI. Phosphate supplementation for hypophosphatemia during continuous renal replacement therapy in adults. Ren Fail. 2019;41(1):72-9.

66. Patel JJ, McClain CJ, Sarav M, Hamilton-Reeves J, Hurt RT. Protein requirements for critically ill patients with renal and liver failure. Nutr Clin Pract. 2017;32(1 suppl):101S-11S.

67. Lambert K, Beer J, Dumont R, Hewitt K, Manley K, Meade A, et al. Weight management strategies for those with chronic kidney disease: a consensus report from the Asia Pacific Society of Nephrology and Australia and New Zealand Society of Nephrology 2016 renal dietitians meeting. Nephrology (Carlton). 2018;23(10):912-20.

68. Kamimura MA, Avesani CM, Bazanelli AP, Baria F, Draibe SA, Cuppari L. Are prediction equations reliable for estimating resting energy expenditure in chronic kidney disease patients? Nephrol Dial Transplant. 2010;26(2):544-50.

69. Hansen HP, Tauber-Lassen E, Jensen BR, Parving HH. Effect of dietary protein restriction on prognosis in patients with diabetic nephropathy. Kidney Int. 2002;62(1):220-8.

70. Cianciaruso B, Pota A, Bellizzi V, Di Giuseppe D, Di Micco L, Minutolo R, et al. Effect of a low- versus moderate-protein diet on progression of CKD: follow-up of a randomized controlled trial. Am J Kidney Dis. 2009;54(6):1052-61.

71. Jesudason DR, Pedersen E, Clifton PM. Weight-loss diets in people with type 2 diabetes and renal disease: a randomized controlled trial of the effect of different dietary protein amounts. Am J Clin Nutr. 2013;98(2):494-501.

72. Sánchez C, Aranda P, Planells E, Galindo P, Pérez de la Cruz A, Larrubia M, et al. Influence of low-protein dietetic foods consumption on quality of life and levels of $\mathrm{B}$ vitamins and homocysteine in patients with chronic renal failure. Nutr Hosp. 2010;25(2):238-44.

73. Meloni C, Morosetti M, Suraci C, Pennafina MG, Tozzo C, Taccone-Gallucci $\mathrm{M}$, et al. Severe dietary protein restriction in overt diabetic nephropathy: benefits or risks? J Ren Nutr. 2002;12(2):96-101.

74. Chauveau P, Barthe N, Rigalleau V, Ozenne S, Castaing F, Delclaux C, et al. Outcome of nutritional status and body composition of uremic patients on a very low protein diet. Am J Kidney Dis. 1999;34(3):500-7.
75. Malvy D, Maingourd C, Pengloan J, Bagros P, Nivet H. Effects of severe protein restriction with ketoanalogues in advanced renal failure. J Am Coll Nutr. 1999;18(5):481-6.

76. Bauer J, Biolo G, Cederholm T, Cesari M, Cruz-Jentoft AJ, Morley JE, et al. Evidence-based recommendations for optimal dietary protein intake in older people: a position paper from the PROT-AGE Study Group. J Am Med Dir Assoc. 2013;14(8):542-59.

77. Kasiske BL, Lakatua JD, Ma JZ, Louis TA. A meta-analysis of the effects of dietary protein restriction on the rate of decline in renal function. Am J Kidney Dis. 1998;31(6):954-61.

78. Rossi M, Johnson DW, Campbell KL. The kidney-gut axis: implications for nutrition care. J Ren Nutr. 2015;25(5):399-403.

79. Ravel VA, Molnar MZ, Streja E, Kim JC, Victoroff A, Jing J, et al. Low protein nitrogen appearance as a surrogate of low dietary protein intake is associated with higher all-cause mortality in maintenancehemodialysispatients. JNutr.2013;143(7):1084-92.

80. Chewcharat A, Takkavatakarn K, Wongrattanagorn S, Panrong K, Kittiskulnam P, Eiam-Ong S, et al. The effects of restricted protein diet supplemented with ketoanalogue on renal function, blood pressure, nutritional status, and chronic kidney disease-mineral and bone disorder in chronic kidney disease patients: a systematic review and meta-analysis. J Ren Nutr. 2020;30(3):189-99.

81. Koppe L, Cassani de Oliveira M, Fouque D. Ketoacid analogues supplementation in chronic kidney disease and future perspectives. Nutrients. 2019;11(9):2071.

82. Garneata L, Stancu A, Dragomir D, Stefan G, Mirescu G. Ketoanalogue supplemented vegetarian very low-protein diet and CKD progression. J Am Soc Nephrol. 2016;27(7):2164-76.

83. Soroka N, Silverberg DS, Greemland M, Birk Y, Blum M, Peer G, et al. Comparison of a vegetable-based (soya) and an animal-based low-protein diet in predialysis chronic renal failure patients. Nephron. 1998;79(2):173-80.

84. Anderson JW, Blake JE, Turner J, Smith BM. Effects of soy protein on renal function and proteinuria in patients with type 2 diabetes. Am J Clin Nutr. 1998;68(6 Suppl):1347S-53S.

85. Wheeler ML, Fineberg SE, Fineberg NS, Gibson RG, Hackward LL. Animal versus plant protein meals in individuals with type 2 diabetes and microalbuminuria: effects on renal, glycemic, and lipid parameters. Diabetes Care. 2001;25(8):1277-82.

86. Scialla JJ, Appel LJ, Wolf M, Yang W, Zhang X, Sozio SM, et al; Chronic Renal Insufficiency Cohort-CRIC Study Group. Plant protein intake is associated with fibroblast growth factor 23 and serum bicarbonate levels in patients with chronic kidney disease: the Chronic Renal Insufficiency Cohort study. J Ren Nutr. 2012;22(4):379-88.

87. Moe SM, Zidehsarai MP, Chambers MA, Jackman LA, Radcliffe JS, Trevino LL, et al. Vegetarian compared with meat dietary protein source and phosphorus homeostasis in chronic kidney disease. Clin J Am Soc Nephrol. 2011;6(2):257-64.

88. Carrero JJ, González-Ortiz A, Avesani CM, Bakker SJL, Bellizzi $\mathrm{V}$, Chauveau $\mathrm{P}$, et al. Plant-based diets to manage the risks and complications of chronic kidney disease. Nat Rev Nephrol. 2020;16(9):525-42.

89. Rastogi A, Bhatt N, Rossetti S, Beto J. Management of hyperphosphatemia in end-stage renal disease: a new paradigm. J Ren Nutr. 2021;31(1):21-34.

90. Clase CM, Carrero JJ, Elison DH, Grams ME, Hemmelgarn BR, Jardine MJ, et al. Potassium homeostasis and management of dyskalemia in kidney disease: conclusions from a Kidney Disease: Improving Global Outcomes (KDIGO) Controversies Conference. Kidney Int. 2020;97(1):42-61.

91. St-Jules DE, Woolf K, Pompeii ML, Ann Sevick M. Exploring problems in following the hemodialysis diet and their relation to energy and nutrient intakes: the BalanceWise Study. J Ren Nutr. 2016;26(2):118-24.

92. Smyth A, Dunkler D, Gao P, Teo KK, Yusuf S, O'Donnell MJ, et al; ONTARGET and TRANSCEND investigators. 
The relationship between estimated sodium and potassium excretion and subsequent renal outcomes. Kidney Int. 2014;86(6):1205-12.

93. Gritter M, Vogt L, Yeung SMH, Wouda RD, Ramakers CRB, Borst $\mathrm{MH}$, et al. Rationale and design of a randomized placebocontrolled clinical trial assessing the renoprotective effects of potassium supplementation in chronic kidney disease. Nephron. 2018;140(1):48-57.

94. Meuleman Y, Hoekstra T, Dekker FW, Navis G, Vogt L, van der Boog PJM, et al; ESMO Study Group. Sodium restriction in patients with CKD: a randomized controlled trial of self-management support. Am J Kidney Dis. 2017;69(5): 576-86

95. Saran R, Padilla RL, Gillespie BW, Heung M, Hummel SL, Derebail VK. A randomized crossover trial of dietary sodium restriction in stage 3-4 CKD. Clin J Am Soc Nephrol. 2017;12(3):399-407.

96. Liang X, Wang W, Li H. Water and sodium restriction on cardiovascular disease in young chronic hemodialysis patients. Chin Med J (Engl). 2013;126(9):1667-72.

97. Bossola M, Pepe G, Vulpio C. The frustrating attempt to limit the interdialytic weight gain in patients on chronic hemodialysis: new insights into an old problem. J Ren Nutr. 2018;28(5):293-301.

98. Jankowska M, Rutkowski B, Dębska-Ślizień A. Vitamins and microelement bioavailability in different stages of chronic kidney disease. Nutrients. 2017;9(3):282.

99. Tucker BM, Safadi S, Friedman AN. Is routine multivitamin supplementation necessary in US chronic adult hemodialysis patients? A systematic review. J Ren Nutr. 2015;25(3):257-64.

100. Kosmadakis G, Costa Correia E, Carceles O, Somda F, Aguilera D. Vitamins in dialysis: who, when and how much? Ren Fail. 2014;36(4):638-50.

101. Salehi M, Sohrabi Z, Ekramzadeh M, Fallahzadeh MK, Ayatollahi M, Geramizadeh B, et al. Selenium supplementation improves the nutritional status of hemodialysis patients: a randomized, double-blind, placebo-controlled trial. Nephrol Dial Transplant. 2013;28(3):716-23.

102. Kistler BM, Benner D, Burrowes JD, Campbell KL, Fouque D, Garibotto G, et al. Eating during hemodialysis treatment: a consensus statement from the International Society of Renal Nutrition and Metabolism. J Ren Nutr. 2018;28(1):4-12.

103. Leonberg-Yoo AK, Wang W, Weiner DE, Lacson E Jr. Oral nutritional supplements and 30-day readmission rate in hypoalbuminemic maintenance hemodialysis patients. Hemodial Int. 2019;23(1):93-100.

104. Fotiadou E, Georgianos PI, Chourdakis M, Zebekakis PE, Liakopoulos V. Eating during the hemodialysis session: a practice improving nutritional status or a risk factor for intradialytic hypotension and reduced dialysis adequacy? Nutrients. 2020;12(6):1703.

105. Sayce HA, Rowe PA, McGonigle RJS. Percutaneous endoscopic gastrostomy feeding in haemodialysis out-patients. J Hum Nutr Diet. 2000;13(5):333-41.

106. Holley JL, Kirk J. Enteral tube feeding in a cohort of chronic hemodialysis patients. J Ren Nutr. 2002;12(3):177-82.

107. Wright M, Southcott E, MacLaughlin H, Wineberg S. Clinical practice guideline on undernutrition in chronic kidney disease. BMC Nephrol. 2019;20(1):370.
108. Brown B, Roehl K, Betz M. Enteral nutrition formula selection: current evidence and implications for practice. Nutr Clin Pract. 2015;30(1):72-85

109. Anderson J, Peterson K, Bourne D, Boundy E. Effectiveness of intradialytic parenteral nutrition in treating protein-energy wasting in hemodialysis: a rapid sistematic review. J Ren Nutr. 2019;29(5):361-9.

110. Cano NJ, Fouque D, Roth H, Aparicio M, Azar R, Canaud B, et al; French Study Group for Nutrition in Dialysis. Intradialytic parenteral nutrition does not improve survival in malnourished hemodialysis patients: a 2-year multicenter, prospective, randomized study. J Am Soc Nephrol. 2007;18(9):2583-91.

111. Marsen TA, Beer J, Mann H; German IDPN-Trial group. Intradialytic parenteral nutrition in maintenance hemodialysis patients suffering from protein-energy wasting. Results of a multicenter, open, prospective, randomized trial. Clin Nutr. 2017;36(1):107-17.

112. Kendrick J, Sharma S, Holmen J, Palit S, Nuccio E, Chonchol M. Kidney disease and maternal and fetal outcomes in pregnancy. Am J Kidney Dis. 2015;66(1):55-9.

113. Bacchetta J, Harambat J, Dubourg L, Guy B, Liutkus A, Canterino I, et al. Both extrauterine and intrauterine growth restriction impair renal function in children born very preterm. Kidney Int. 2009;76(4):445-52.

114. Esposito P, Garibotto G, Picciotto D, Costigliolo F, Viazzi F, Conti NE. Nutritional challenges in pregnant women with renal diseases: relevance to fetal outcomes. Nutrients. 2020;12(3):873.

115. Reyes-López MA, Piccoli GB, Leone F, Orozco-Guillén A, Perichart-Perera O. Nutrition care for chronic kidney disease during pregnancy: an updated review. Eur J Clin Nutr. 2020;74(7):983-90.

116. Attini R, Leone F, Parisi S, Fassio F, Capizzi I, Loi V, et al. Vegan-vegetarian low-protein supplemented diets in pregnant CKD patients: fifteen years of experience. BMC Nephrol. 2016;17(1):132.

117. Piccoli GB, Leone F, Attini R, Parisi S, Fassio F, Deagostini MC. Association of low-protein supplemented diets with fetal growth in pregnant women with CKD. Clin J Am Soc Nephrol. 2014;9(5):864-73.

118. Shaw V, Polderman N, Renken-Terhaerdt J, Paglialonga F, Oosterveld M, Tuokkola J, et al. Energy and protein requirements for children with CKD stages 2-5 and on dialysis-clinical practice recommendations from the Pediatric Renal Nutrition Taskforce. Pediatr Nephrol. 2020;35(3):519-31.

119. Hui WF, Betoko A, Savant JD, Abraham AG, Greenbaum LA, Warady B, et al. Assessment of dietary intake of children with chronic kidney disease. Pediatr Nephrol. 2017;32(3):485-94.

120. Nixon AC, Bampouras TM, Pendleton N, Woywodt A, Mitra S, Dhaygude A. Frailty and chronic kidney disease: current evidence and continuing uncertainties. Clin Kidney J. 2018;11(2):236-45.

121. Gomes-Neto AW, Osté MCJ, Sotomayor CG, van den Berg E, Geleijnse JM, Berger SP, et al. Mediterranean style diet and kidney function loss in kidney transplant recipients. Clin J Am Soc Nephrol. 2020;15(2):238-46.

122. Tantisattamo E, Kalantar-Zadeh K, Halleck F, Duettmann W, Naik M, Budde K. Novel approaches to sarcopenic obesity and weight management before and after kidney transplantation. Curr Opin Nephrol Hypertens. 2021;30(1):14-26.

Conflito de interesse: Os autores Clarissa Martins Saraiva Figueira Zambelli, Juliana Tepedino Martins Alves, Guilherme Teixeira de Araújo, Renata Cristina Campos Goncalves, MariaHelena Lima Gusmão,AnaAdélia CavalcanteHordonho, Fernando das Mercês de Lucas Júnior, Juliano Antunes Machado, Juliana de Carvalho Machado, Marcelo Mazza do Nascimento e Cristina Martins declaram não haver Rodrigo Costa Gonçalves declara palestras para Fresenius, Baxter, Danone, Nestlé e Novo Nordisk 
